Key Words:

Mixing

Simulant

Pilot-scale

Tank

Retention:

Permanent

DEMONSTRATION OF SIMULATED WASTE TRANSFERS FROM TANK AY-102 TO THE HANFORD WASTE TREATMENT FACILITY

\author{
D. J. Adamson \\ M. R. Poirier \\ T. J. Steeper
}

NOVEMBER, 2009

Savannah River National Laboratory

Savannah River Nuclear Solutions

Aiken, SC 29808 


\section{DISCLAIMER}

This work was prepared under an agreement with and funded by the U.S. Government. Neither the U. S. Government or its employees, nor any of its contractors, subcontractors or their employees, makes any express or implied:

1. warranty or assumes any legal liability for the accuracy, completeness, or for the use or results of such use of any information, product, or process disclosed; or

2. representation that such use or results of such use would not infringe privately owned rights; or

3. endorsement or recommendation of any specifically identified commercial product, process, or service.

Any views and opinions of authors expressed in this work do not necessarily state or reflect those of the United States Government, or its contractors, or subcontractors.

Printed in the United States of America

Prepared for

U.S. Department of Energy 
Key Words:

Transfer

Simulant

Tank

Retention:

Permanent

\title{
DEMONSTRATION SIMULATED WASTE TRANSFERS FROM TANK AY-102 TO THE HANFORD WASTE TREATMENT FACILITY
}

\author{
D. J. Adamson \\ M. R. Poirier \\ T. J. Steeper
}

NOVEMBER 2009

Savannah River National Laboratory

Savannah River Nuclear Solutions

Aiken. SC 29808

Prepared for the U.S. Department of Energy Under

Contract Number DE-AC09-08SR22470

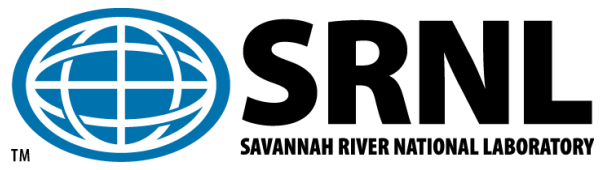




\section{REVIEWS AND APPROVALS}

D. J. Adamson, Co-author, Engineering Development Laboratory

Date

M. R. Poirier, Co-author, Separations Science Programs

Date

M. L. Restivo, Technical Review, Engineering Development Laboratory

Date

B. J. Giddings, Manager, Engineering Development Laboratory

Date

S. L. Marra, Manager, Environmental \& Chemical Process Technology Research Date

M. G. Thien, WRPS Task Lead

Date

- ii - 


\section{TABLE OF CONTENTS}

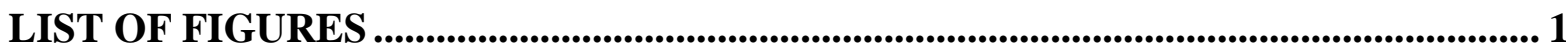

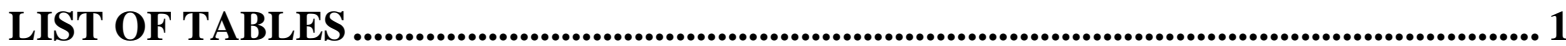

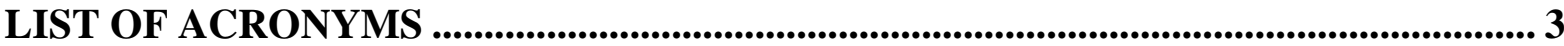

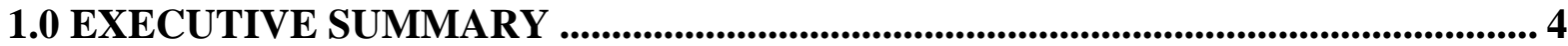

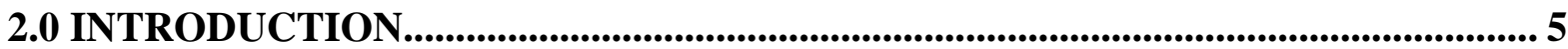

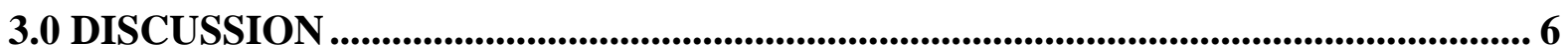

3.1 Experimental Approach and Setup............................................................................... 6

3.1.1 Test Results ........................................................................................................................... 17

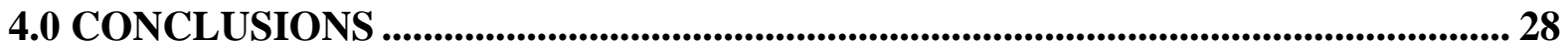

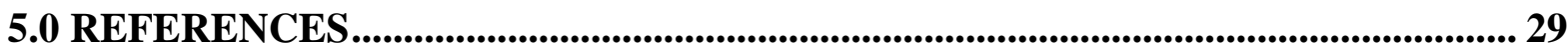

APPENDIX A: R \& D Direction for DEMONSTRATION of SIMULATED WASTE TRANSFERS FROM TANK AY-102 TO THE HANFORD WASTE TREATMENT

FACILITY .................................................................................................................................. 30

APPENDIX B: Drawings ........................................................................................................... 43

APPENDIX C: PSD Analysis of SiC Tests 11 and 3.5............................................................. 47

\section{LIST OF FIGURES}

Figure 1: Drawing of the Transfer Demonstration Test System ........................................... 7

Figure 2: Receipt Tank Drawing ..................................................................................................... 11

Figure 3: Top View of MDT Transfer Lines locations (Point 1 and 3 tested) ................ 14

Figure 4: MDT, Settled Solids....................................................................................................... 15

Figure 5: Drive Assembly for MJP Rotation (guard in place)............................................... 16

Figure 6: Picture of the Transfer Demonstration System .................................................... 17

Figure 7: Solids Settled in the Receipt Tanks of Test 2 (1 day settling)........................... 18

Figure 8: Solids Settled in the Receipt Tanks (1 day settling) ............................................ 19

Figure 9: SiC Settled in the Receipt Tanks.............................................................................. 21

Figure 10: Two Dead Zones in MDT at the end of Test 10 ................................................ 22

Figure 11: Test 11 Settling of Solids, 1 day vs. 3 days settling time .................................. 23

Figure 12: Tests 1, 5, 9, 11 and 3.5 Volume of Total Settled Solids.................................... 24

Figure 13: Receipt Tank SiC Level Test 6 (1 day settling)..................................................... 25

Figure 14: Solids Pumped from MDT, Test 6 .............................................................................. 26

Figure 15: PSD Samples from Test 3.5, (1 day of settling)................................................... 27

\section{LIST OF TABLES}

Table 1: Full Size and Scaled Parameters ................................................................................... 8

Table 2: Instrument List ................................................................................................................. 9

Table 3: Receipt Tank Calibrations .............................................................................................. 12

Table 4: Test Matrix for Transfer Demonstrations........................................................... 13 
Table 5: Total Solids Transferred to Receipt Tanks (1 day settling).

Table 6: Total Sic Transferred to Receipt Tanks Settling (20 minutes after transfer). 20

Table 7: Total Solids in Receipt Tanks, Two days or More Settling Time. 23

Table 8: PSD from Test 11 and Test 3.5 


\section{LIST OF ACRONYMS}

$\begin{array}{ll}\text { DST } & \text { Double shell tank } \\ \text { EDL } & \text { Engineering Development Laboratory } \\ \text { gpm } & \text { Gallons per minute } \\ \text { MDT } & \text { Mixing Demonstration Tank } \\ \text { MJP } & \text { Mixing Jet Pumps } \\ \text { OD } & \text { Outer diameter } \\ \text { PVC } & \text { Polyvinyl Chloride } \\ \text { rpm } & \text { Revolutions per minute } \\ \text { SiC } & \text { Silicon Carbide } \\ \text { SRNL } & \text { Savannah River National Laboratory } \\ \text { Sst } & \text { Stainless steel } \\ \text { TTQAP } & \text { Task Technical and Quality Assurance Plan } \\ \text { TTR } & \text { Task Technical Request } \\ \text { WRPS } & \text { Washington River Protection Solutions } \\ \text { WTP } & \text { Waste Treatment Plant }\end{array}$




\subsection{EXECUTIVE SUMMARY}

In support of Hanford's AY-102 Tank waste certification and delivery of the waste to the Waste Treatment and Immobilization Plant (WTP), Savannah River National Laboratory (SRNL) was tasked by the Washington River Protection Solutions (WRPS) to evaluate the effectiveness of mixing and transferring the waste in the Double Shell Tank (DST) to the WTP Receipt Tank. This work is a follow-on to the previous "Demonstration of Internal Structures Impacts on Double Shell Tank Mixing Effectiveness" task conducted at SRNL ${ }^{1}$.

The objective of these transfers was to qualitatively demonstrate how well waste can be transferred out of a mixed DST tank and to provide insights into the consistency between the batches being transferred. Twelve (12) different transfer demonstrations were performed, varying one parameter at a time, in the Batch Transfer Demonstration System. The work focused on visual comparisons of the results from transferring six batches of slurry from a $1 / 22^{\text {nd }}$ scale (geometric by diameter) Mixing Demonstration Tank (MDT) to six Receipt Tanks, where the consistency of solids in each batch could be compared. The simulant used in this demonstration was composed of simulated Hanford Tank AZ-101 supernate, gibbsite particles, and silicon carbide particles, the same simulant/solid particles used in the previous mixing demonstration.

Changing a test parameter may have had a small impact on total solids transferred from the MDT on a given test, but the data indicates that there is essentially no impact on the consistency of solids transferred batch to batch.

Of the multiple parameters varied during testing, it was found that changing the nozzle velocity of the Mixer Jet Pumps (MJPs) had the biggest impact on the amount of solids transferred. When the MJPs were operating at $8.0 \mathrm{gpm}\left(22.4 \mathrm{ft} / \mathrm{s}\right.$ nozzle velocity, $\mathrm{U}_{\mathrm{o}} \mathrm{D}=0.504$ $\mathrm{ft}^{2} / \mathrm{s}$ ), the solid particles were more effectively suspended, thus producing a higher volume of solids transferred. When the MJP flow rate was reduced to $5 \mathrm{gpm}(14 \mathrm{ft} / \mathrm{s}$ nozzle velocity, $\mathrm{U}_{\mathrm{o}} \mathrm{D}=0.315 \mathrm{ft}^{2} / \mathrm{s}$ ) to each pump, dead zones formed in the tank, resulting in fewer solids being transferred in each batch to the Receipt Tanks. The larger, denser particles were displaced (preferentially to the smaller particles) to one of the two dead zones and not re-suspended for the duration of the test.

As the liquid level dropped in the MDT, re-suspending the particles became less effective $\left(6^{\text {th }}\right.$ batch). The poor consistency of the solids transferred in the $6^{\text {th }}$ batch was due to low liquid level in the MDT, thus poor mixing by the MJPs.

Of the twelve tests conducted the best transfer of solids occurred during Test 6 and 8 where the MJP rotation was reduced to $1.0 \mathrm{rpm}$. 


\subsection{INTRODUCTION}

The Hanford double shell tank (DST) system provides the staging location for feeding tank waste to the Waste Treatment and Immobilization Plant (WTP). ICD 19-Interface Control Document for Waste Feed Delivery (24590-WTP-ICD-MG-01-019) includes WTP acceptance criteria that describe physical and chemical characteristics of the waste that must be certified as acceptable prior to waste transfer from the DSTs to the WTP. The baseline feed delivery concept includes equipment capable of mixing the DST waste, obtaining representative samples of the DST contents, and delivering waste to the WTP within acceptable tolerance bands of waste chemical and physical properties. Understanding the three dimensional performance of the DST mixing systems is necessary to define the specific functional requirements of the DST sampling and feed transfer systems. The early stages of the Waste Feed Delivery Demonstration Program are focused on demonstrating in a scaled environment the performance of mixing the contents in a DST tank and transferring the contents out of the tank.

During the previous "Demonstration of Internal Structures Impacts on Double Shell Tank Mixing Effectiveness" task, it was determined that the obstructions in the $1 / 22^{\text {nd }}$ scale Mixing Tank had little if any negative impact on tank mixing. Visually there was very little difference, if any, in mixing the contents of the tank with the obstructions in or out of the tank ${ }^{1}$. During the mixing demonstrations, the contents of the $1 / 22^{\text {nd }}$ scale MDT could be mixed well (no dead zones) but the contents of the tank were never homogenous.

This report focuses on the batch transfer demonstrations from the $1 / 22^{\text {nd }}$ scale MDT to six individual Receipt Tanks. This testing models the batch transfers from the AY-102 Tanks to the WTP receipt tank where HLW slurry will be delivered in 160,000 gallon batches. 


\subsection{DISCUSSION}

\subsection{EXPERIMENTAL APPROACH AND SETUP}

The test system used for the batch transfer demonstrations is shown in Figure 1. The Transparent MDT (1/22 ${ }^{\text {nd }}$ scale), along with internal obstructions, was used in the previous test, "Demonstration of Internal Structures Impacts on Double Shell Tank Mixing

Effectiveness" ". The tank had an ID of 40.5" and a height of 30". The bottom of the tank was transparent to aid in visual observations.

There were a total of 22 air lift circulators (ALC), a heating coil, a transfer pump feed line and two Mixer Jet Pumps (MJPs) that mimicked the obstructions in the MDT. The obstructions were geometrically scaled to the AY-102 Tank. The obstructions were in the MDT for all transfer demonstrations since it was found the obstructions had essentially no impact on the mixing in the MDT. As found during the previous study, the critical dimension of the obstructions was the distance the ALCs were off the bottom of the tank (30" in the full-scale tank). This clearance off the bottom of the tank allows for the MJPs to mix all areas without the obstructions causing blockage. The slurry pump that fed the mixer jets was located external to the MDT and was controlled by a variable speed drive. The test fluid was pumped from the MDT and then circulated back to the $1 / 22^{\text {nd }}$ scale Mixer Jet Pumps. Detail drawings of the Mixing Jet Pumps and the obstructions are given in Appendix B. 


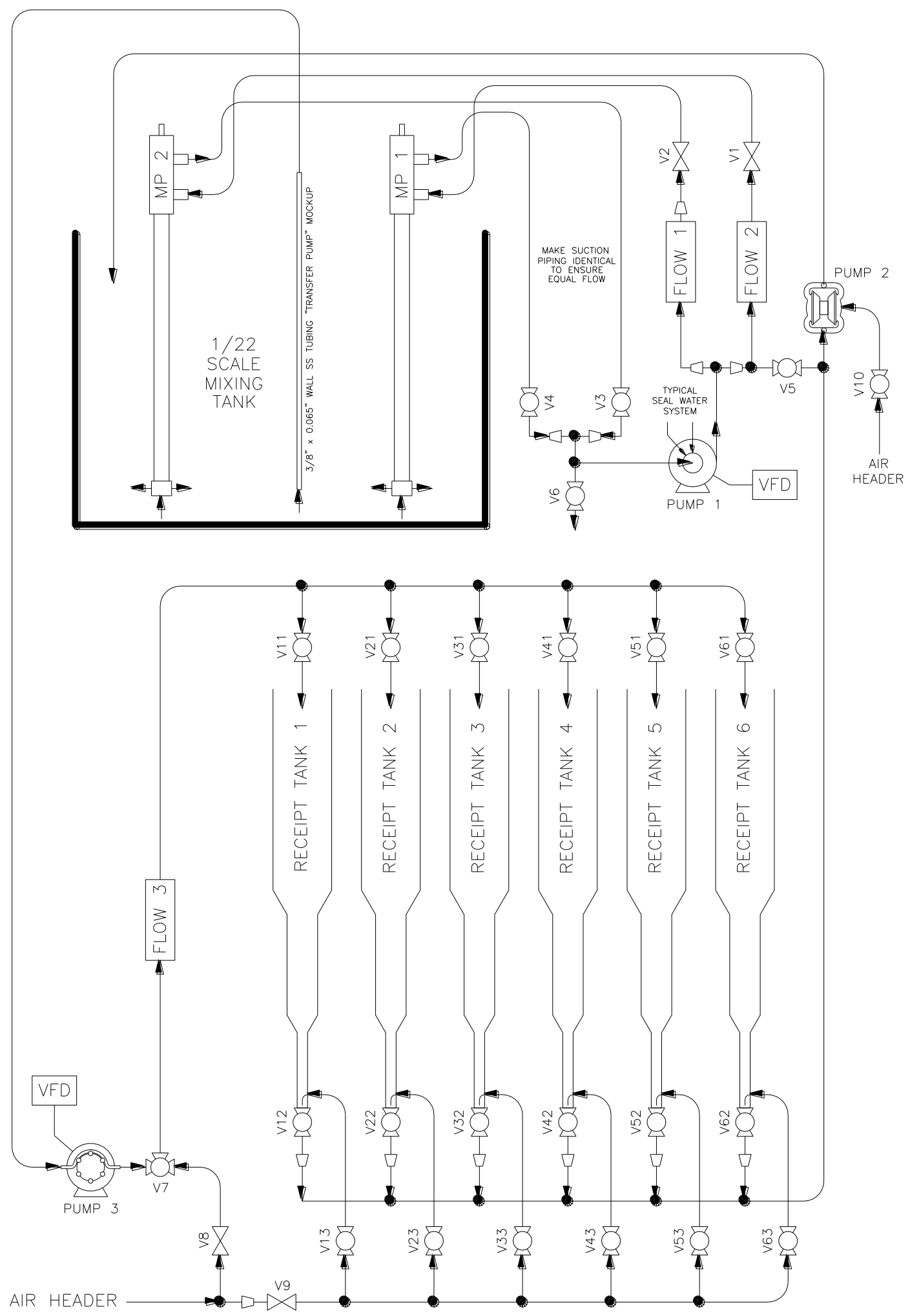

Figure 1: Drawing of the Transfer Demonstration Test System 
Table 1 provides important parameters associated with the AY-102 Tank and the $1 / 22^{\text {nd }}$ scale MDT and transfer system.

Table 1: Full Size and Scaled Parameters

\begin{tabular}{|c|c|c|}
\hline Parameter Description AY-102 & Full Scale & Model@ $1 / 22=0.045$ scale factor \\
\hline Tank diameter & $75 \mathrm{ft}$ (900 inches) & 40.5 inches (actual 40.9”) \\
\hline Tank operating height & 364 inches & 16.5 inches \\
\hline Total waste height & 347 inches & 15.6 inches \\
\hline Sludge height & 55 inches & 2.49 inches (actual 1.75") \\
\hline Supernate height & 292 inches & 13.2 inches \\
\hline Total waste volume & $955,085 \mathrm{gal}$ & 87 gallons \\
\hline Batch volume to WTP & 160,000 gal & 14.3 gal \\
\hline Residence mixing time AY-102 & 45.2 minutes & \\
\hline $\begin{array}{l}\text { Flow for scaled model to have full } \\
\text { scale residence time }\end{array}$ & - & $0.47 \mathrm{gal} / \mathrm{min} /$ nozzle \\
\hline $\begin{array}{l}\text { Nozzle velocity at full-scale } \\
\text { residence }\end{array}$ & - & $2.6 \mathrm{ft} / \mathrm{sec}$ \\
\hline Pump location from tank center & $22 \mathrm{ft}$ & 11.9 inches \\
\hline Pump above tank bottom & 6 inches & 0.27 inches \\
\hline Nozzle diameter & 6 inches & 0.27 inches \\
\hline $\begin{array}{l}\text { Nozzle location from bottom of } \\
\text { pump }\end{array}$ & 9 inches & 0.41 inches \\
\hline Pump rotational speed & $0.2 \mathrm{rpm}$ & $0.2 \mathrm{rpm}, 1.0 \mathrm{rpm}, 4.4 \mathrm{rpm}$ \\
\hline $\begin{array}{l}\text { Pump flowrate } \\
\text { Nozzle Exit Velocity }\end{array}$ & $\begin{array}{l}5280 \mathrm{gal} / \mathrm{min} / \text { nozzle } \\
60 \mathrm{ft} / \mathrm{sec}\end{array}$ & $\begin{array}{l}10.8 \mathrm{gal} / \mathrm{min} / \text { nozzle } \\
60 \mathrm{ft} / \mathrm{sec}\end{array}$ \\
\hline $\mathrm{U}_{\mathrm{o}} \mathrm{D}$ & $30 \mathrm{ft}^{2} / \mathrm{s}$ & $1.35 \mathrm{ft}^{2} / \mathrm{s}$ \\
\hline $\mathrm{U}_{\mathrm{o}} \mathrm{D}$ at a flowrate of $8 \mathrm{gpm} \mathrm{MJP}$ & & $0.504 \mathrm{ft}^{2} / \mathrm{s}$ \\
\hline $\mathrm{U}_{\mathrm{o}} \mathrm{D}$ at a flowrate of $5 \mathrm{gpm}$ MJP & & $0.315 \mathrm{ft}^{2} / \mathrm{s}$ \\
\hline $\begin{array}{l}1 / 22^{\text {nd }} \text { Pump flowrate }(8 \mathrm{gpm}) \\
\text { Nozzle Exit Velocity }\end{array}$ & - & $\begin{array}{l}4 \mathrm{gal} / \mathrm{min} / \text { nozzle } \\
22.4 \mathrm{ft} / \mathrm{sec} / \text { nozzle }\end{array}$ \\
\hline $\begin{array}{l}1 / 22^{\text {nd }} \text { Pump flowrate }(5 \mathrm{gpm}) \\
\text { Nozzle Exit Velocity }\end{array}$ & $\begin{array}{l}- \\
-\end{array}$ & $\begin{array}{l}2.5 \mathrm{gal} / \mathrm{min} / \text { nozzle } \\
14 \mathrm{ft} / \mathrm{sec} / \text { nozzle }\end{array}$ \\
\hline Pump flowrate (power cal.) & $5280 \mathrm{gal} / \mathrm{min} /$ nozzle & $5.0 \mathrm{gal} / \mathrm{min} / \mathrm{nozzle}$ \\
\hline Nozzle velocity (power calculation) & $60 \mathrm{ft} / \mathrm{sec}$ & $28 \mathrm{ft} / \mathrm{sec}$ \\
\hline $\mathrm{U}_{\mathrm{o}} \mathrm{D}$ (power calculation) & - & $0.63 \mathrm{ft}^{2} / \mathrm{s}$ \\
\hline Liquid density & $1,150 \mathrm{~kg} / \mathrm{m}^{3}$ & $1,289 \mathrm{~kg} / \mathrm{m}^{3}$ \\
\hline Solids density & $2,500 \mathrm{~kg} / \mathrm{m}^{3}$ & $\begin{array}{l}\text { Gibbsite: } 2,420 \mathrm{~kg} / \mathrm{m}^{3} \\
\text { SiC: } 3,217 \mathrm{~kg} / \mathrm{m}^{3}\end{array}$ \\
\hline Viscosity of liquid & $2.8 \mathrm{cP}$ & $2.55 \mathrm{cP}$ \\
\hline Air mixers (22 in tank) & 30 inches & $1.35 "$ (used 1.25”) \\
\hline Air mixers above tank bottom & 30 inches & 1.35 inches \\
\hline Heating coil dia (1 in tank) & 40.375 inches & $1.8 "$ (used 1.75") \\
\hline Transfer pump outer diameter & 12 inches & 0.54 " (used 3/8" sst tube) \\
\hline Transfer pump inlet diameter & 2.25 inches & $0.1 "$ (used $0.125 ")$ \\
\hline Transfer pump above tank bottom & 5 inches & 0.23 inches \\
\hline Transfer pump, pump rate & $90-140 \mathrm{gpm}$ & $0.29 \mathrm{gpm}, 0.58 \mathrm{gpm}$ \\
\hline Transfer pump, velocity & $3.9 \mathrm{ft} / \mathrm{s}, 6.1 \mathrm{ft} / \mathrm{s}$ & $3.6 \mathrm{ft} / \mathrm{s}, 7.2 \mathrm{ft} / \mathrm{s}$ \\
\hline Batch transfer volume & $160,000 \mathrm{gal}$ & 14.3 gal \\
\hline Particle size distribution & $2.5 \sim 16.8 \mu \mathrm{m}$ & $\begin{array}{l}\text { SiC }-50 \text { to } 165 \mu \mathrm{m} \\
\text { Gibbsite } 30 \mu \mathrm{m}, \mathrm{Max}\end{array}$ \\
\hline
\end{tabular}


To mimic the transfer system from the AY-102 Tank, a transfer pump was added to pump batches of simulant from the MDT to each of the six Receipt Tanks.

A Moyno Pump, Model 33201 (0.13 to 2.0 GPM flow rate) was used to make the batch transfers. The transfer pump is Pump 3 in Figure 1. The transfer pump had no problems handling the anticipated wear from the $\mathrm{SiC}$ material used in the tank.

The transfer flow rate from the MDT to the Receipt Tanks was scaled by time and volume. When scaled by time, the flow rate was $0.29 \mathrm{gpm}(7.5 \mathrm{ft} / \mathrm{sec})$. When we scaled by volume, the flow rate was $5.2 \mathrm{gpm}$. At $0.29 \mathrm{gpm}$, the transfer time is approximately 50 minutes. At $5.2 \mathrm{gpm}$, the transfer time is less than 3 minutes. Therefore time scaling was chosen for testing. For all but three tests the velocity was increased to $15 \mathrm{ft} / \mathrm{sec}$, resulting in a flow rate of $0.58 \mathrm{gpm}$. A $1 / 4$ "stainless steel tubing, 035" wall was used from Pump 3 to the Receipt Tanks 3/8", 035" wall stainless steel tubing was used at the transfer line suction point in the MDT. Flexible 3/8" tubing was used from the MDT to the transfer pump.

The test was designed such that six independent batch transfers could be made from the MDT. This simulates the multiple 160,000 gallon batches that will be transferred to the WTP. Figure 1 shows valving configurations for the batch transfers of simulant to be pumped from the MDT to the six Receipt Tanks.

Three flow meters were used in the transfer demonstrations to measure the flow rate of simulant being sent to the MJPs and the batch transfers. Table 2 provides an instrument list along with calibration information of the instruments.

Table 2: Instrument List

\begin{tabular}{|c|c|c|c|}
\hline M\&TE \# & Description & Calibration range & Uncertainty \\
\hline TR-03811 & $\begin{array}{c}\text { Magnetic flow meter, ABB } \\
\text { Instrumentation Inc. }\end{array}$ & $0-25 \mathrm{gpm}$ & $\pm 0.22 \mathrm{gpm}$ \\
\hline TR-03674 & $\begin{array}{c}\text { Magnetic flow meter, ABB } \\
\text { Instrumentation Inc. }\end{array}$ & $0-25 \mathrm{gpm}$ & $\pm 0.18 \mathrm{gpm}$ \\
\hline TR-03680 & $\begin{array}{c}\text { Magnetic flow meter, } \\
\text { Fischer Porter for Transfers }\end{array}$ & $0-1.6 \mathrm{gpm}$ & $\pm 0.009 \mathrm{gpm}$ \\
\hline
\end{tabular}

Six (6) Receipt Tanks were designed and constructed for the six batch transfers from the MDT. The tanks are transparent (clear PVC) on the lower section of the tank (except for reducers) to allow for measuring the volume of solids that were transferred in each batch. As shown in Figure 2, the bottom section of the tank makes a smooth transfer from a 6", schedule 40 pipe (between point 3 and point 4) to a 3", schedule 40 transparent PVC pipe (between point 1 and point 2). The transparent section of the Receipt Tank was designed to hold approximately 4.3 gallons. This ensured that an accurate measurement of the solids transferred in each batch could be obtained. 
The Receipt Tanks holds approximately 22 gallons. Each tank was calibrated at five different elevations. Point 5, the maximum volume (14.3 gallons) that would be transferred in each batch, was in the opaque section of the tank. A sight glass was added to determine the level in this section of the tank. Table 3 gives the calibration data of each of the six Receipt Tanks. The points in column 1 of the table correspond to the points in Figure 2. For example, point 3 of Receipt Tank 2 is at 30" with a volume of 1.23 gallons. 


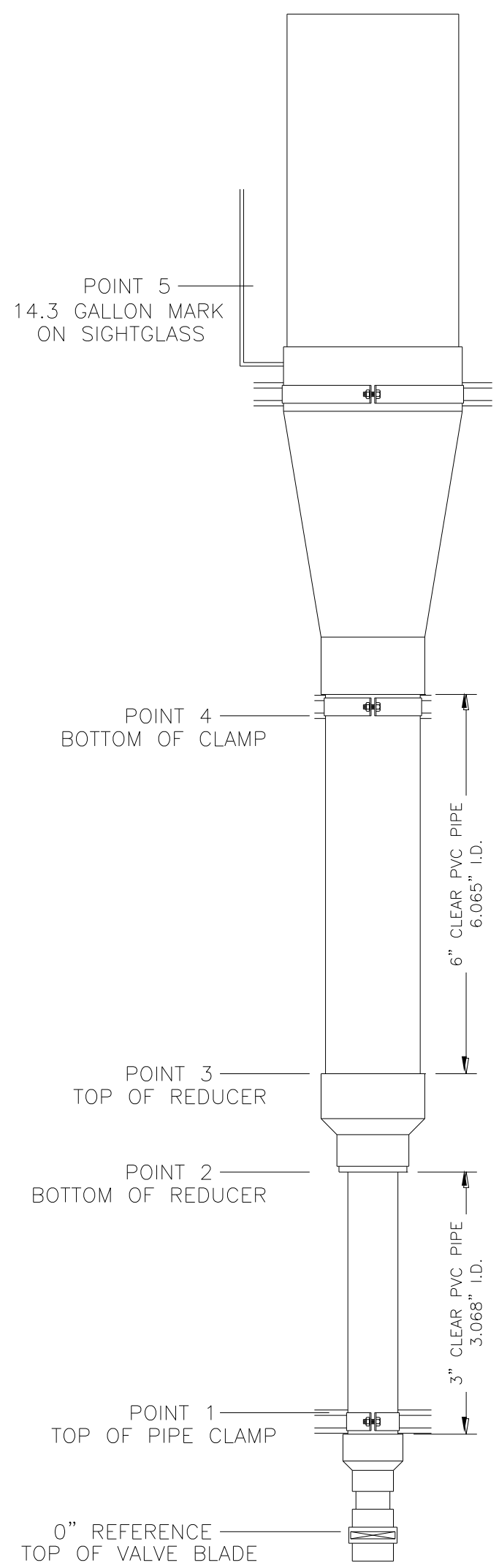

Figure 2: Receipt Tank Drawing 
SRNL-STI-2009-00717

Table 3: Receipt Tank Calibrations

\begin{tabular}{|c|c|c|c|c|c|c|c|c|c|c|c|c|}
\hline & \multicolumn{2}{|l|}{ Receipt Tank 1 } & \multicolumn{2}{l|}{ Receipt Tank 2 } & \multicolumn{2}{l|}{ Receipt Tank 3 } & \multicolumn{2}{l|}{ Receipt Tank 4 } & \multicolumn{2}{l|}{ Receipt Tank 5 } & \multicolumn{2}{l|}{ Receipt Tank 6 } \\
\hline Point & inch & gallon & inch & gallon & inch & gallon & inch & gallon & inch & gallon & inch & gallon \\
\hline 1 & 8.38 & 0.26 & 8.38 & 0.19 & 8.32 & 0.20 & 8.56 & 0.19 & 8.75 & 0.20 & 8.69 & 0.21 \\
\hline 2 & 23.06 & 0.74 & 23.06 & 0.65 & 23.06 & 0.66 & 23.06 & 0.65 & 23.13 & 0.66 & 23.13 & 0.66 \\
\hline 3 & 30.00 & 1.32 & 30.00 & 1.23 & 30.06 & 1.22 & 30.13 & 1.23 & 29.94 & 1.23 & 30.00 & 1.26 \\
\hline 4 & 55.00 & 4.40 & 55.00 & 4.30 & 55.00 & 4.30 & 55.00 & 4.31 & 54.75 & 4.29 & 54.63 & 4.32 \\
\hline 5 & - & 14.30 & - & 14.30 & - & 14.30 & - & 14.30 & - & 14.30 & - & 14.30 \\
\hline
\end{tabular}

Air spargers were placed in the bottom of each of the Receipt Tanks. The spargers were used to mix the simulant in the Receipt Tanks before pumping their contents back to the MDT.

During Test 1 the spargers were used to mix the contents of the Receipt Tanks to determine if a better measurement could be made of the SiC transferred in each batch. Once the Receipt Tanks were mixed, the contents of the tanks were allowed to settle over night. It was determined that this process did not allow for a better measurement of the SiC transferred when compared to the natural settling during the batch transfers.

The operating liquid level in the scaled MDT was scaled from the total liquid level (347') currently in the AY-102. The mixing demonstration used 15.7" to 16 " of simulant to be geometrically scaled with the Hanford tanks.

When the MDT liquid level dropped to approximately 1.5" during tank mixing, The MJPs began to pull in air, impacting mixing during the last batch transferred $\left(6^{\text {th }}\right.$ transfer) on each test. The flow rate supplied to the MJPs was slowly decreased during batch 6 until the mixing was completely stopped before the end of batch 6 . Batch 6 continued until 14.3 gallons was transfer into Receipt Tank 6 or the Transfer pump started pulling in air, ending the transfer. At the end of the $6^{\text {th }}$ transfer there was approximately 1.5 gallons $(1$ " in the MDT equals 5.58 gallons) or more of simulant left in the MDT.

Testing was conducted per the R\&D Direction in Appendix A. Test results were also recorded in a Laboratory Notebook, SRNL-NB-2009-00014.

\section{Simulant}

The same supernate and solids that were used in the Mixing Demonstrations were used for the transfer demonstrations. The supernate used was prepared from a previous task at SRNL. This simulant was intended to represent an average Hanford tank waste. The supernate itself is transparent. The recipe for this simulant is given in the "Revised Preparation of Simulated Feed Solution for Pilot Plant”, CH2M-0701541.1 report (July, 2007). The recipe was modified from the report; the sodium dichromate was not added to the simulant to prevent it from being a hazardous solution. Gibbsite (30 $\mu \mathrm{m}$ maximum particle size) and $\mathrm{SiC}$ (50 to $165 \mu \mathrm{m})$ particles were added to act as the tank sludge. The particles size distribution reported here is from the vendor. Each demonstration was conducted using the same 87 gallons (15.6") of simulant that was used in the Mixing Demonstration. There was approximately $82.6 \mathrm{lb}$ of gibbsite and $9.3 \mathrm{lb}$ of $\mathrm{SiC}$ in the MDT at the start of each test. 
Twelve tests, consisting of six batch transfers in each test, were conducted. These transfers mimicked the number of 160,000 gallons batch transfers that would be required from the AY-102 tank with 1,000,000 gallons of stored waste. Table 4 lists the twelve demonstrations in the order they were conducted.

Table 4: Test Matrix for Transfer Demonstrations

\begin{tabular}{|c|c|c|c|c|c|c|}
\hline \multirow[t]{2}{*}{ Test \# } & \multirow{2}{*}{$\begin{array}{l}\text { Location of } \\
\text { Transfer } \\
\text { pump } \\
\text { in tank }\end{array}$} & \multirow{2}{*}{$\begin{array}{l}\text { Transfer } \\
\text { Type }\end{array}$} & \multirow{2}{*}{$\begin{array}{l}\text { Elevation of } \\
\text { Transfer Pump } \\
\text { suction } \\
\text { (inches) }\end{array}$} & \multirow{2}{*}{$\begin{array}{l}\text { Transfer } \\
\text { from } \\
\text { Mixing } \\
\text { Tank } \\
\text { (gpm) } \\
\end{array}$} & \multicolumn{2}{|c|}{ Mixer Jet pumps } \\
\hline & & & & & $\begin{array}{l}\text { Rotation } \\
\text { (rpm) }\end{array}$ & $\begin{array}{l}\text { Flowrate } \\
\text { (gpm) }\end{array}$ \\
\hline 1 & 1 (baseline) & Batch (6 days) & 0.25 & 0.29 & 4.4 & 8.0 \\
\hline 2 & 1 (baseline) & Continuous & 0.25 & 0.29 & 4.4 & 8.0 \\
\hline 3 & 1 (baseline) & Continuous & 0.25 & 0.58 & 4.4 & 8.0 \\
\hline 4 & 1 (baseline) & Continuous & $2.0 \quad(8 X)$ & 0.58 & 4.4 & 8.0 \\
\hline 5 & 1 (baseline) & Continuous & 0.25 & 0.58 & 4.4 & 5.0 \\
\hline 6 & 1 (baseline) & Continuous & 0.25 & 0.58 & $1.0(5 X)$ & 8.0 \\
\hline 7 & 3 (riser \# 1) & Continuous & 0.25 & 0.58 & 4.4 & 8.0 \\
\hline 8 & 3 (riser \# 1) & Continuous & 0.25 & 0.58 & $1.0(5 \mathrm{X})$ & 8.0 \\
\hline 9 & 3 (riser \# 1) & Continuous & $2.0 \quad(8 X)$ & 0.58 & 4.4 & 8.0 \\
\hline 10 & 3 (riser \# 1) & Continuous & 0.25 & 0.58 & 4.4 & 5.0 \\
\hline 11 & 3 (riser \# 1) & Continuous & 0.25 & 0.29 & 4.4 & 8.0 \\
\hline 3.5 & \multicolumn{6}{|c|}{ Duplicate Test 3 to demonstrate repeatability of data } \\
\hline
\end{tabular}

Test 3.5 was originally planned to be between Tests 3 and 4 . However, it was decided during Test 3 to move Test 3.5 to the end of the test campaign at the request of WRPS. In each of the tests, only one parameter was changed at a time. For the location of the transfer pump suction line, two points were tested. Point 1 is the baseline point and the location of the fullscale Transfer Pump in the AY-102 Tank. Point 3 (Riser \#1 on the AY-102 Tank) was on a line passing through the center of the tank that is perpendicular to the line connecting the two mixer pumps (M). Figure 3 depicts these locations in the $1 / 22^{\text {nd }}$ scale MDT. Points 2 and 4 on the drawing were proposed to transfer from but were not tested. 


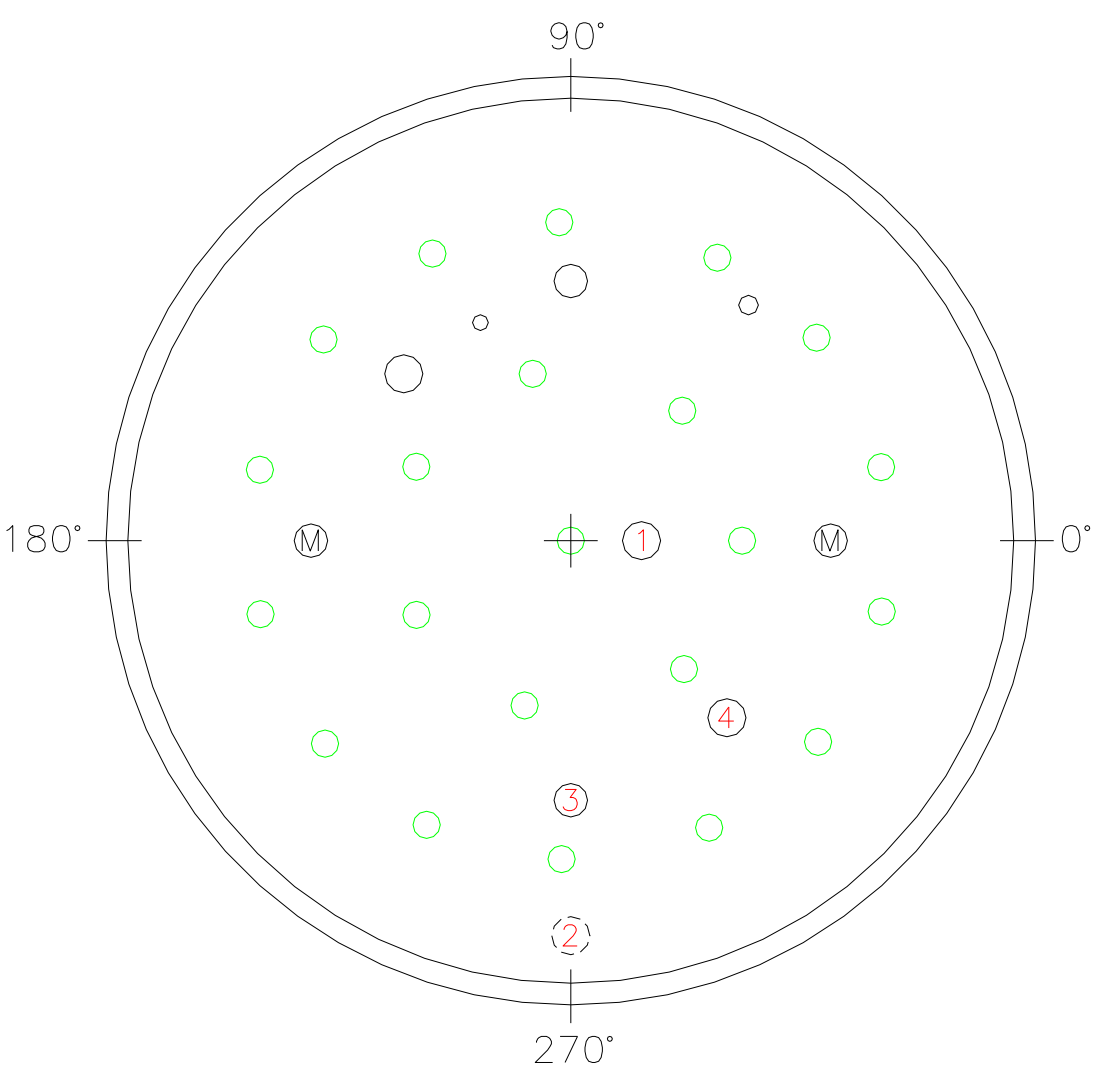

Figure 3: Top View of MDT Transfer Lines locations (Point 1 and 3 tested)

The transfer type was either batch or continuous. The batch transfer on Test 1 was more true to what will occur on the batch transfers from the AY-102 Tank to the WTP. In between each transfer, the contents of the MDT were allowed to settle for approximately 24 hours. This would allow for the contents of the MDT to settle before being remixed for the following batch transfer. The continuous transfer is where the contents of the MDT were mixed and not allowed to settle between batches and the transfer pump was not turned off between batches. Once a batch of 14.3 gallons was transferred to a Receipt Tank, the valve line up was changed, sending the following batch to the next Receipt Tank. This change was made to allow testing to be completed in a shorter time. Figure 4 is a picture of the MDT after the $\mathrm{SiC}$ and gibbsite solids were allowed to settle for more than a day. 


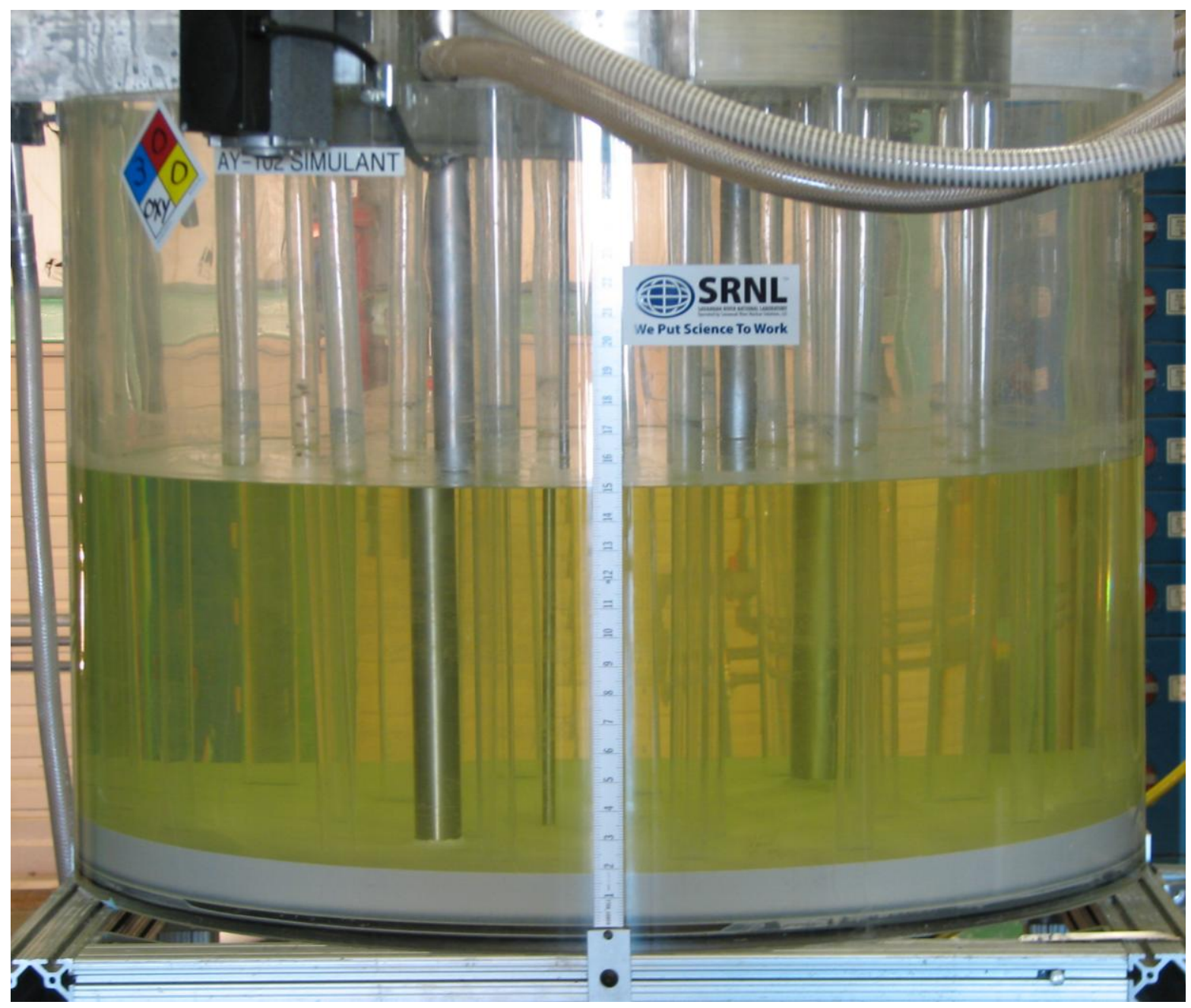

\section{Figure 4: MDT, Settled Solids}

The elevation of the transfer line, above the bottom of the MDT was tested at two different heights, 0.25 " $\left(1 / 22^{\text {nd }}\right.$ scale of the AY-102 transfer pump) and 2.0" (8 times the baseline).

The flow rate of the batch transfers from the MDT to the Receipt Tanks was tested at two different flows, $0.29 \mathrm{gpm}$ and $0.58 \mathrm{gpm}$. Over the test campaign, the flow rate of the transfers was found to be very consistent and accurate. This was determined by timing the transfers and measuring the total volume.

Two rotational speeds of the MJPs were tested during the transfer demonstrations, $4.4 \mathrm{rpm}$ and $1.0 \mathrm{rpm}$ (MJPs full-scale AY-102 Tank rotation is $0.2 \mathrm{rpm}$ ). In scaling the MJP rotation speed between the full-scale tank and the pilot-scale tank, the following approach was used. As the MJP rotates, it lifts particles off of the tank bottom. Some of the particles will be lifted to the top of the liquid, and then settle back to the tank bottom. Since the particle settling rate is the same in both tanks, they will need less time to settle to the bottom in the MDT. Because the liquid level in the MDT is $1 / 22$ of the liquid level in the full-scale tank, 
the time to settle a scaled distance in the MDT is $1 / 22$ the time in the full-scale tank. Therefore, we selected a pump rotation rate of $4.4 \mathrm{rpm}(0.2 \mathrm{rpm} \times 22)$ so that the particles that are lifted by the pump in the full-scale and settle before the jet rotates around will see the same phenomenon in the pilot-scale tank. The $1.0 \mathrm{rpm}$ MJP rotation speed test condition was selected to determine if a major change in the MJP rotational speed would have an impact on tank mixing and the solids transfer.

Figure 5 below is a picture of the chain and sprocket assembly used to rotate the Mixer Jet Pumps. The rotation system was modified to obtain a rotational speed of $4.4 \mathrm{rpm}$, up from the rotation system used during the AY-102 tank mixing demonstrations, $0.2-0.7 \mathrm{rpm}$. Each pump had its own drive assembly and motor. The drive motors were connected to one motor controller, and consequently were given the same frequency adjusted power. This resulted in fairly uniform rotational speed.

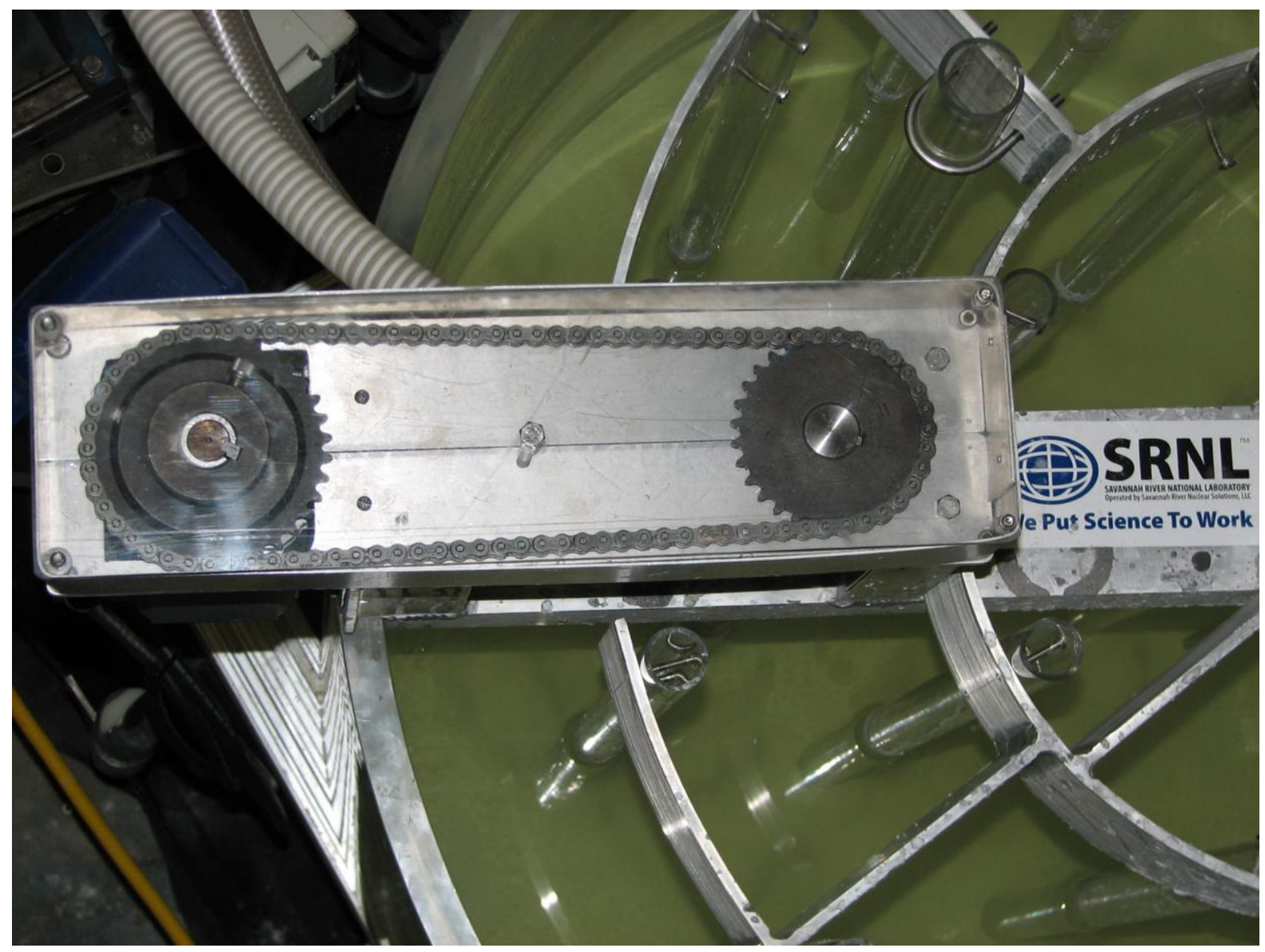

Figure 5: Drive Assembly for MJP Rotation (guard in place)

Both MJPs rotated counter clockwise and for the most part at the same speed using one motor controller. But conditions existed (i.e., friction in the pumps from the $\mathrm{SiC}$ ) where one pump rotated slightly slower than the other during the six batch transfers. From this it was conjectured that the jet position between the two pumps may have some impact on the 
mixing. Additional testing and studies may be needed to determine whether synchronous operation of the two MJPs (i.e. optimization of the synchronous phase angle between separate nozzle rotations) impacts the suspension of solids.

The simulant in the MDT was mixed at two different flow rates supplied to each Mixer Jet Pump, 8.0 gpm (velocity, $22.4 \mathrm{ft} / \mathrm{s} /$ nozzle) and $5.0 \mathrm{gpm}$ (velocity, $14 \mathrm{ft} / \mathrm{s} / \mathrm{nozzle}$ ). $8.0 \mathrm{gpm}$ was chosen due to this being the lowest flow rate to each MJP where no dead zones existed in the MDT. This data was obtained during the mixing study.

\subsubsection{Test Results}

All transfer demonstrations were conducted in the pilot-scale system shown in Figure 6. The test system was designed and constructed at SRNL. The picture shows the $1 / 22^{\text {nd }}$ scaled MDT on the left and the six Receipt Tanks to the right.

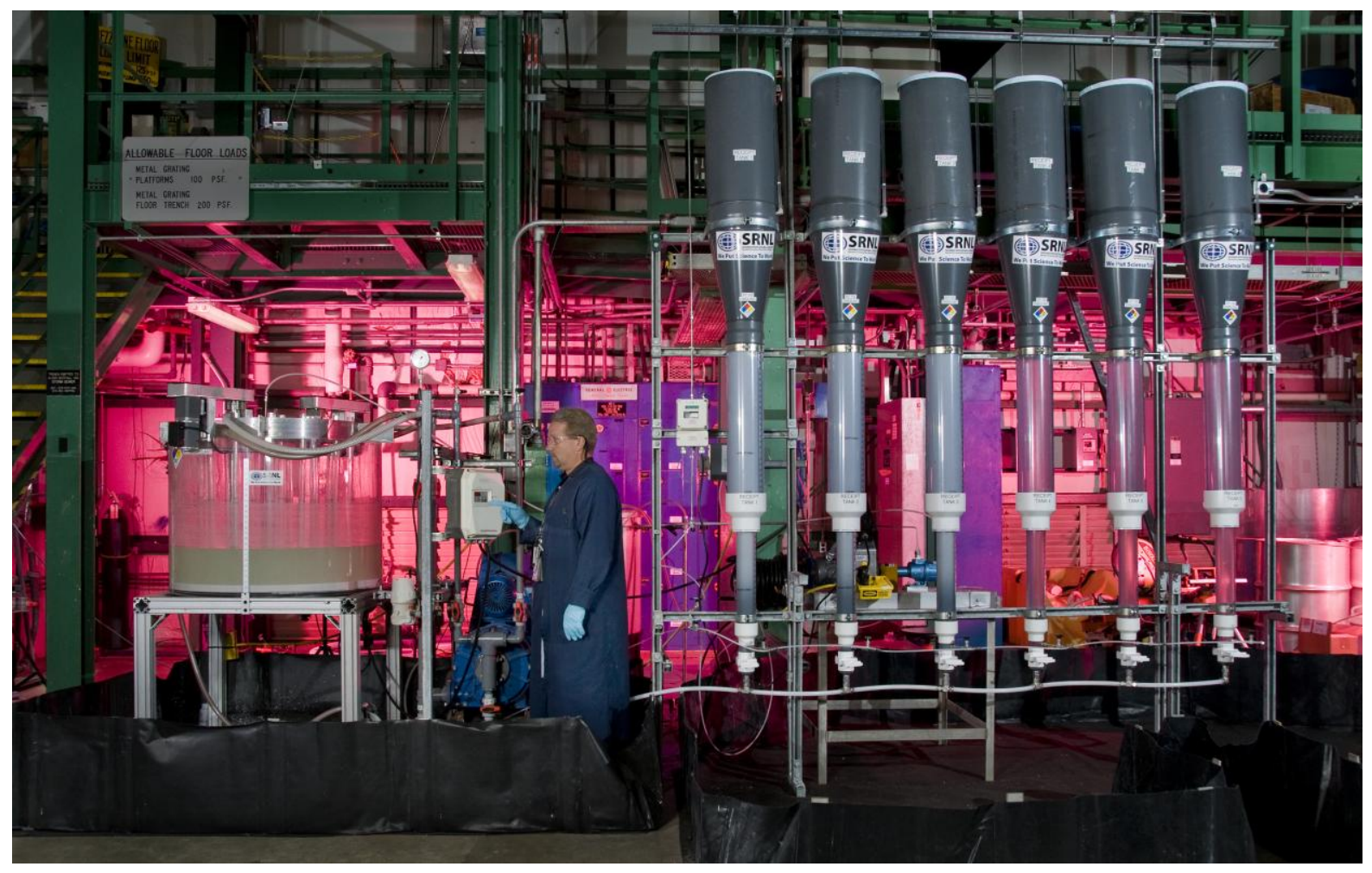

Figure 6: Picture of the Transfer Demonstration System

A total of twelve transfer demonstrations tests were conducted using the same simulant in each demonstration. Each test consisted of six batch transfers that were pumped to individual Receipt Tanks. 
After each test, the batch transfers to the Receipt Tanks were allowed to settle at a minimum overnight. Figure 7 is a picture showing the solids in each of the six Receipt Tanks after settling overnight on Test 2.

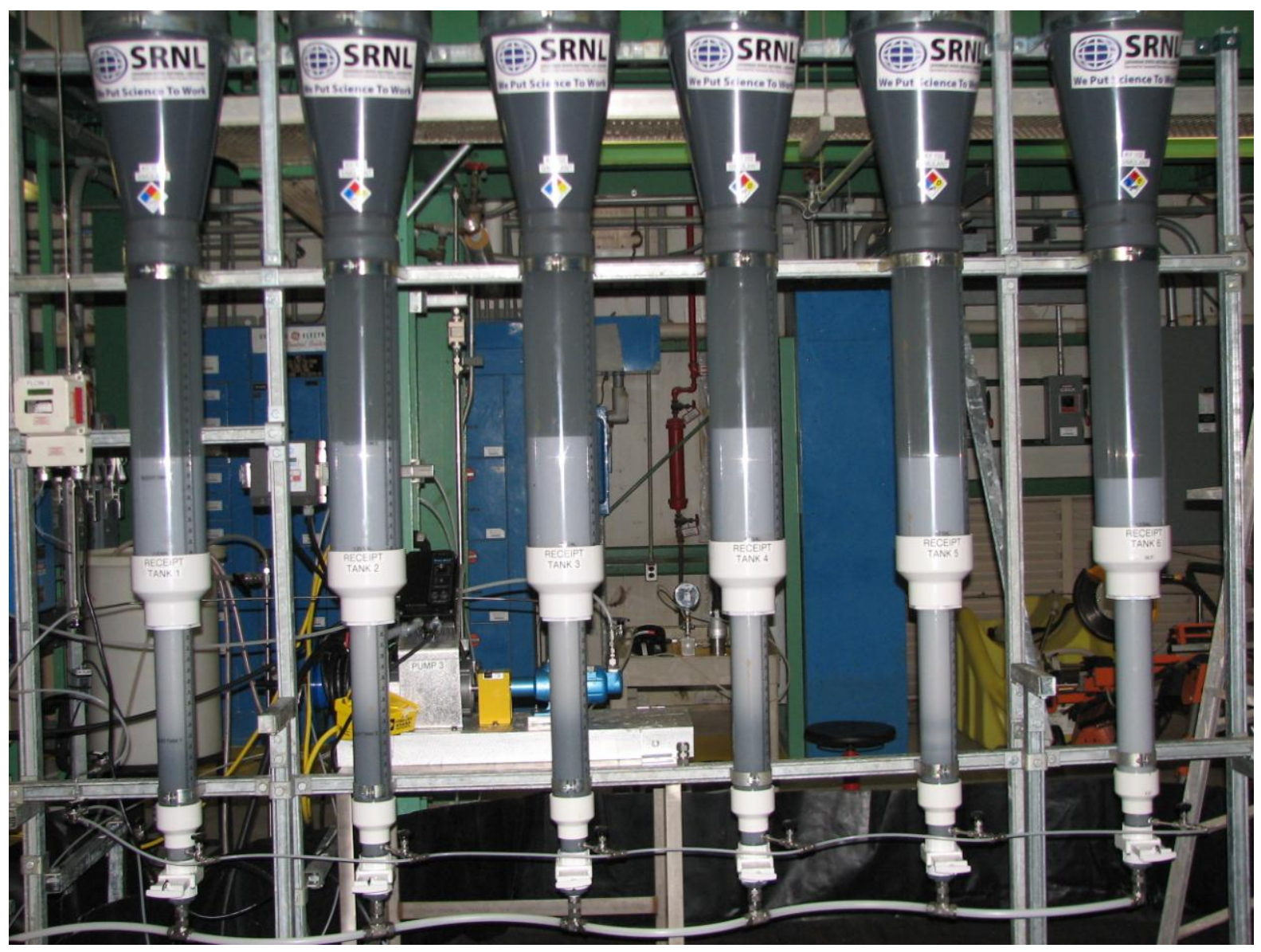

Figure 7: Solids Settled in the Receipt Tanks of Test 2 (1 day settling)

Table 5 gives the total height of solids ( $\mathrm{SiC}$ and Gibbsite) in each Receipt Tank for each of the 12 tests conducted. The measurements were taken after settling in the Receipt Tanks for about a day. It is important to note that it took about two days of settling time for the solids to settle completely. The Receipt Tanks where allowed to settled for two days or more on Tests $1,5,9,11$, and 3.5. The volume of solids transferred is discussed in more detail later in this report. 
Table 5: Total Solids Transferred to Receipt Tanks (1 day settling)

\begin{tabular}{|c|c|c|c|c|c|c|}
\hline & $\begin{array}{c}\text { Receipt } \\
\text { Tank 1, } \\
\text { inches }\end{array}$ & $\begin{array}{c}\text { Receipt } \\
\text { Tank 2, } \\
\text { inches }\end{array}$ & $\begin{array}{c}\text { Receipt } \\
\text { Tank 3, } \\
\text { inches }\end{array}$ & $\begin{array}{c}\text { Receipt } \\
\text { Tank 4, } \\
\text { inches }\end{array}$ & $\begin{array}{c}\text { Receipt } \\
\text { Tank 5, } \\
\text { inches }\end{array}$ & $\begin{array}{c}\text { Receipt } \\
\text { Tank 6, } \\
\text { inches }\end{array}$ \\
\hline Test 1 & 37.63 & 40.38 & 41.63 & 36.88 & 36.56 & 27.00 \\
\hline Test 2 & 39.88 & 40.94 & 41.00 & 41.38 & 38.19 & 35.44 \\
\hline Test 3 & 39.81 & 40.13 & 40.44 & 41.00 & 40.38 & 35.13 \\
\hline Test 4 & 37.50 & 38.50 & 38.50 & 38.75 & 38.31 & 26.50 \\
\hline Test 5 & 36.25 & 36.75 & 37.13 & 37.63 & 38.00 & 38.00 \\
\hline Test 6 & 37.88 & 38.19 & 40.69 & 40.75 & 40.25 & 40.38 \\
\hline Test 7 & 41.88 & 42.25 & 42.50 & 42.75 & 42.68 & 41.75 \\
\hline Test 8 & 41.00 & 41.06 & 41.06 & 41.19 & 41.06 & 40.13 \\
\hline Test 9 & 38.19 & 38.75 & 38.75 & 39.00 & 38.50 & 26.50 \\
\hline Test 10 & 42.75 & 43.06 & 43.63 & 43.50 & 43.69 & 42.63 \\
\hline Test 11 & 38.50 & 38.13 & 37.75 & 38.00 & 36.94 & 35.13 \\
\hline Test 3.5 & 40.63 & 41.88 & 42.00 & 42.31 & 41.88 & 40.88 \\
\hline
\end{tabular}

Note: See Table 4 for operating conditions of each test

Figure 8 shows the data from Table 5 in graph form. After one day of settling, the batch transfers are quite similar except for the transfers to Receipt Tank 6(Batch 6 was affected by upstream poor mixing in the MDT).

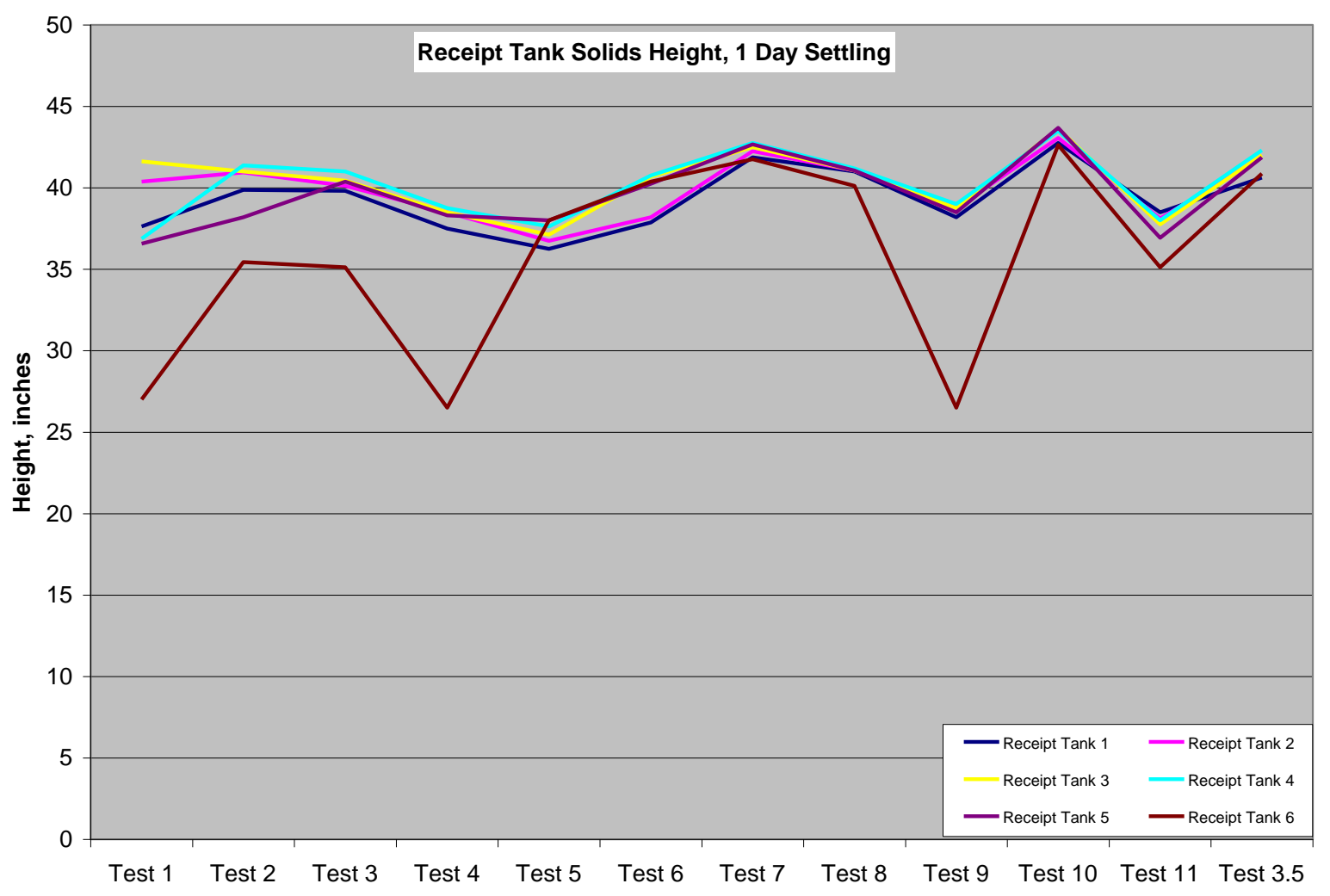

Figure 8: Solids Settled in the Receipt Tanks (1 day settling) 
The transfer of solids on the $6^{\text {th }}$ batch was impacted by poor mixing in the MDT when the liquid level was low and the transfer suction line high (Tests 4 and 9). Another impact realized on the $6^{\text {th }}$ batch is the requirement to regulate the speed of the MJPs as the liquid level dropped in the MDT. In full scale DST operation it is estimated that mixer pumps cannot be operated at full speed when the liquid level drops below approximately 6 feet. If the flow rate to the MJPs were slowly decreased to prevent air from being sucked in, the MJPs would continue to mix the contents of the MDT fairly well to pump out more solids on the $6^{\text {th }}$ batch (last batch).

Table 6 gives the measured height of the SiC settled to the bottom of each Receipt Tank. It was discovered during Tests 1 and 2 that the $\mathrm{SiC}$ had settled with a clear line of transition from the $\mathrm{SiC}$ and the gibbsite in each batch approximately 20 minutes after the transfer was completed.

Table 6: Total SiC Transferred to Receipt Tanks Settling (20 minutes after transfer)

\begin{tabular}{|c|c|c|c|c|c|c|}
\hline & $\begin{array}{c}\text { Receipt } \\
\text { Tank 1, } \\
\text { inches }\end{array}$ & $\begin{array}{c}\text { Receipt } \\
\text { Tank 2, } \\
\text { inches }\end{array}$ & $\begin{array}{c}\text { Receipt } \\
\text { Tank 3, } \\
\text { inches }\end{array}$ & $\begin{array}{c}\text { Receipt } \\
\text { Tank 4, } \\
\text { inches }\end{array}$ & $\begin{array}{c}\text { Receipt } \\
\text { Tank 5, } \\
\text { inches }\end{array}$ & $\begin{array}{c}\text { Receipt } \\
\text { Tank 6, } \\
\text { inches }\end{array}$ \\
\hline Test 1 ** & 11.25 & 13.00 & 14.00 & 13.00 & 12.50 & 7.50 \\
\hline Test 2 ** & 12.50 & 14.00 & 14.00 & 13.50 & 13.00 & 4.50 \\
\hline Test 3 & 14.38 & 14.00 & 14.50 & 14.19 & 12.81 & 9.38 \\
\hline Test 4 & 13.38 & 14.25 & 14.50 & 13.25 & 13.78 & 7.13 \\
\hline Test 5 & 2.75 & 2.75 & 2.63 & 2.63 & 2.63 & 0.00 \\
\hline Test 6 & 14.63 & 15.00 & 14.63 & 14.44 & 14.19 & 13.25 \\
\hline Test 7 & 14.00 & 14.25 & 14.50 & 15.00 & 14.25 & 11.75 \\
\hline Test 8 & 14.50 & 14.75 & 14.50 & 14.38 & 14.25 & 13.00 \\
\hline Test 9 & 13.50 & 14.75 & 15.68 & 14.63 & 12.25 & 0.00 \\
\hline Test 10*** & 0.00 & 0.00 & 0.00 & 0.00 & 0.00 & 0.00 \\
\hline Test 11 & 13.75 & 16.38 & 16.25 & 16.00 & 13.63 & 9.63 \\
\hline Test 3.5 & 15.75 & 14.44 & 14.13 & 14.06 & 12.88 & 7.00 \\
\hline
\end{tabular}

** Settling time for $\mathrm{SiC}$ on first two tests was 1 day ***While some $\mathrm{SiC}$ was observed to be transferred, in most batches it was not easily measured due to the small amount, therefore all $\mathrm{SiC}$ data for test 10 is recorded as zero in this report

In Tests 5 and 10, the MJPs were operated at $5.0 \mathrm{gpm}$, very little $\mathrm{SiC}$ was transferred in each batch as shown in Figure 9. In these two tests, the $\mathrm{SiC}$ settled in one of the two dead zones. Once the material settled into the dead zone, it remained there for the duration of the test. 


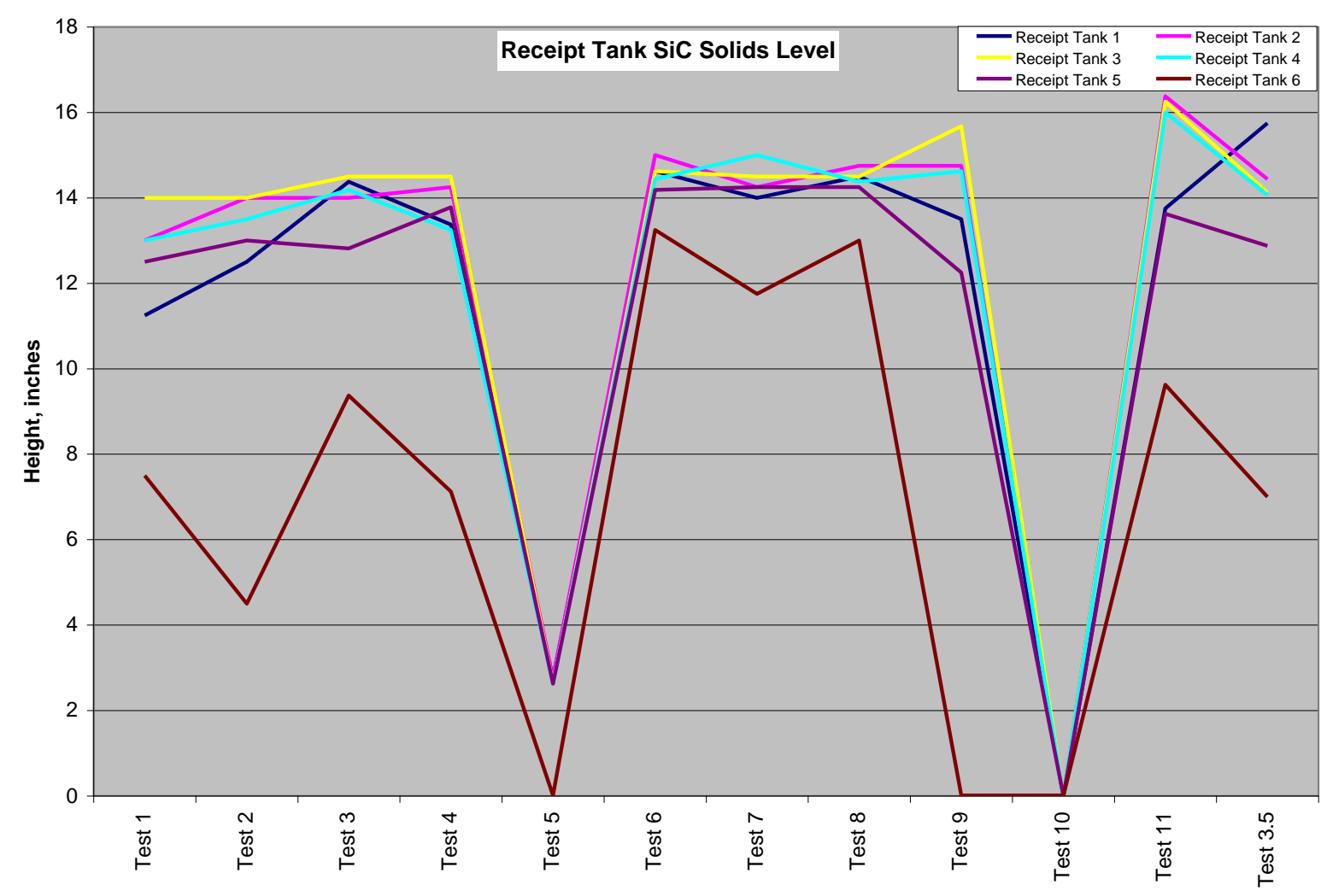

\section{Figure 9: SiC Settled in the Receipt Tanks}

The $\mathrm{SiC}$ transferred on the $6^{\text {th }}$ batch was always the lowest when compared to the previous five batches. The most SiC transferred during the $6^{\text {th }}$ batch occurred on Test 6 and Test 8 . These are the two tests where the MJPs were operated at $8 \mathrm{gpm}$ while rotating at $1.0 \mathrm{rpm}$. This observation suggests that that the mixer pump rotational speed played a role in a better transfer of solids.

The MJPs operating at $5.0 \mathrm{gpm}(14 \mathrm{ft} / \mathrm{s})$ resulted in poor mixing in the MDT. Figure 10 is a picture of the material that was in the two dead zones at the end of the Test 10. In Test 10 there was minimal $\mathrm{SiC}$ observed in the six batch transfers. The two dead zones were 180 degrees apart from each other, the furthest distance from the two Mixer Jet Pumps. The picture on the left is on the south wall and the picture on the right was on the north wall of the MDT. The rest of the tank was essentially clean except for fines of gibbsite in the $1 / 2$ " of simulant in the bottom of the MDT when the transfer ended. 

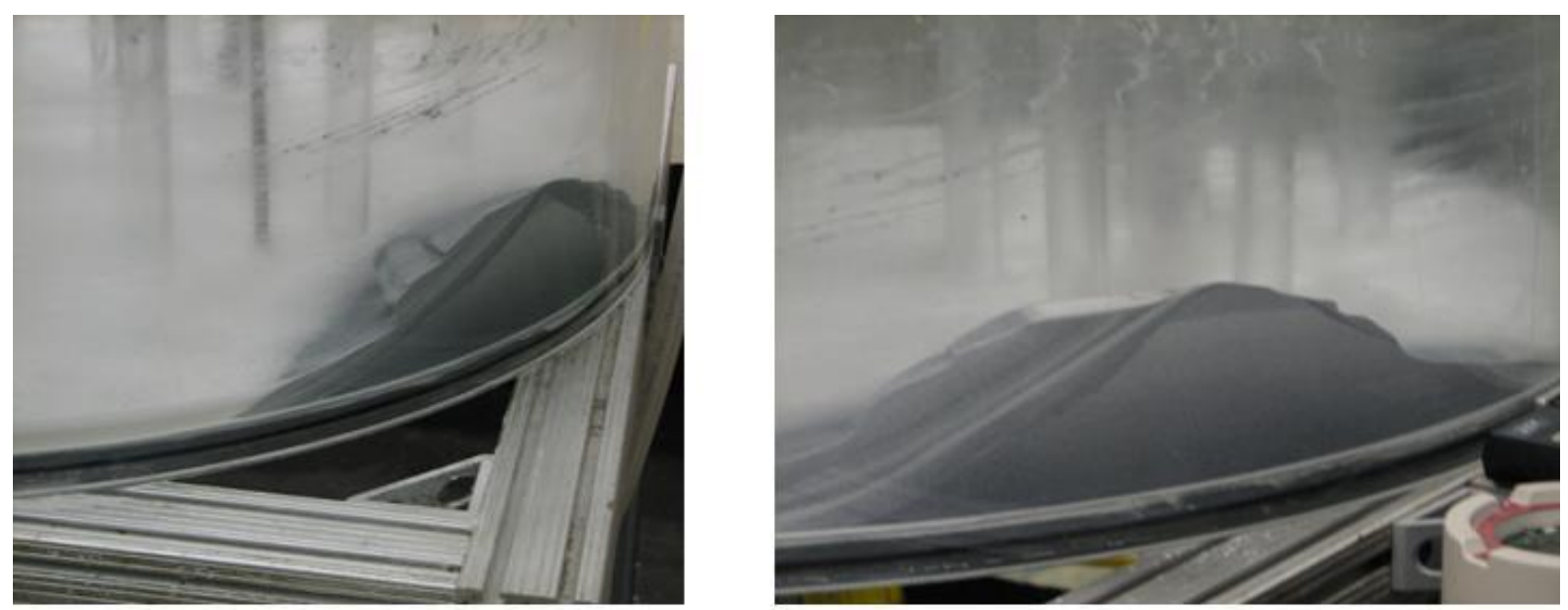

Figure 10: Two Dead Zones in MDT at the end of Test 10

When a dead zone formed, it consisted predominately of SiC particles. For all tests except Test 6 , dead zones typically started forming during the $3^{\text {rd }}$ batch, suggesting the MJP nozzle line up and or the liquid level in the MDT played a role in mixing and transfer of solids. Tests 6 with MJP operating at $8.0 \mathrm{gpm}$, rotating at $1.0 \mathrm{rpm}$ and the transfer suction line at baseline location, showed no dead zones throughout the six batch transfers. Test 8 had only a small amount of material in the dead zones. Test 8 operated at the same parameters as Test 6 , except for the suction line was off-center (location 3, see Figure 3).

The solids in the Receipt Tank do not settle completely in one day. It was found that the contents of the Receipt Tanks settled an additional 15\% to 20\% in height (in the 6" clear pipe) from one day settling to three day settling. Figure 11 gives a visual indication of how the solids settled in Test 11 from one day settling time to three day settling time. For all practical purposes the solids in the Receipt Tanks had settled completely in about two days. To ensure consistency between solid measurements, total solids levels were recorded after settling for approximately a day so that a comparison could be made between the twelve tests.
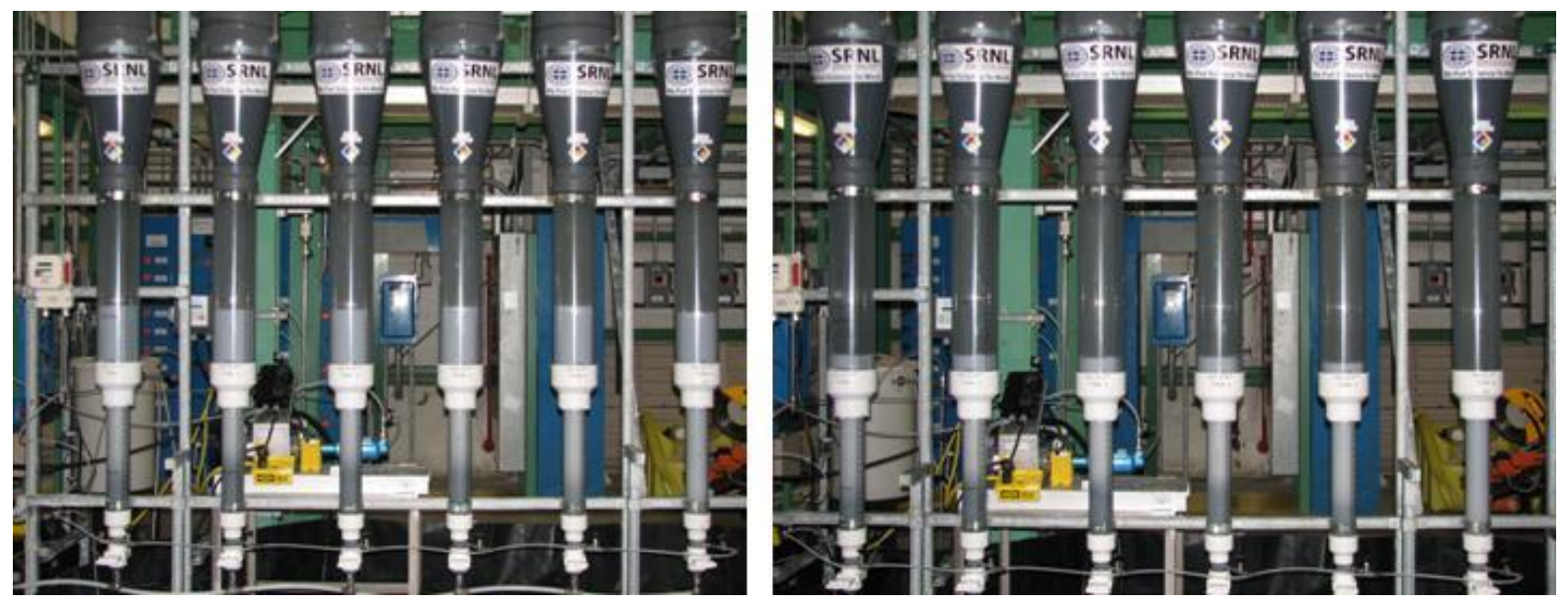
Figure 11: Test 11 Settling of Solids, 1 day vs. 3 days settling time

As depicted in the pictures, Receipt Tanks $1-5$ settled an additional 15\%. Receipt Tanks 6 settled a little more than $20 \%$. On all tests, Receipt Tank 6 settled more than the other five tanks when comparing one day settling to more than two day settling. This may be due to more fines being transferred on the $6^{\text {th }}$ batch.

There were five transfer demonstrations where the solids settled in the Receipt Tanks for two days or more, Tests 1, 5, 9, 11 and 3.5. Table 7 gives the inches and volume of total solids (gibbsite and $\mathrm{SiC}$ ) in each Receipt Tank after two pus days of settling time.

Table 7: Total Solids in Receipt Tanks, Two days or More Settling Time

\begin{tabular}{|l|c|c|c|c|c|c|c|c|c|c|c|c|}
\hline & \multicolumn{2}{|c|}{ RT 1 } & \multicolumn{2}{c|}{ RT 2 } & \multicolumn{2}{c|}{ RT 3 } & \multicolumn{2}{c|}{ RT 4 } & \multicolumn{2}{c|}{ RT 5 } & \multicolumn{2}{c|}{ RT 6 } \\
\cline { 2 - 15 } & inches & gal & inches & gal & inches & gal & inches & gal & inches & gal & inches & gal \\
\hline Test 1 & 31.38 & 1.49 & 32.25 & 1.51 & 31.88 & 1.45 & 32.00 & 1.46 & 31.13 & 1.37 & 26.56 & 0.83 \\
\hline Test 5 & 30.50 & 1.38 & 30.13 & 1.24 & 29.94 & 1.21 & 29.94 & 1.20 & 29.94 & 1.23 & 30.88 & 1.37 \\
\hline Test 9 & 33.25 & 1.72 & 34.00 & 1.72 & 33.88 & 1.69 & 34.25 & 1.74 & 33.38 & 1.65 & 17.38 & 0.50 \\
\hline Test 11 & 32.13 & 1.58 & 32.25 & 1.51 & 32.13 & 1.48 & 32.25 & 1.49 & 32.31 & 1.52 & 27.50 & 0.95 \\
\hline Test 3.5 & 33.44 & 1.74 & 33.25 & 1.63 & 33.13 & 1.60 & 33.44 & 1.64 & 32.75 & 1.57 & 30.9 & 1.34 \\
\hline
\end{tabular}

Out of the twelve transfer demonstrations tests, these five tests are well suited for comparing volumes of solids transferred to the Receipt Tanks. For the other seven transfer demonstrations the solids Receipt Tanks were not settled. Thus the amount of solids transferred to each Receipt Tank would be over estimated for there tests. The material balance for these five tests in Table 7 is realistic since the amount of solids transferred is less that the total volume of solids that were in the MDT at the start of the transfer.

Figure 12 depicts the volume of solids settled in each of the six batches during Tests 1, 5, 9, 11 and 3.5 


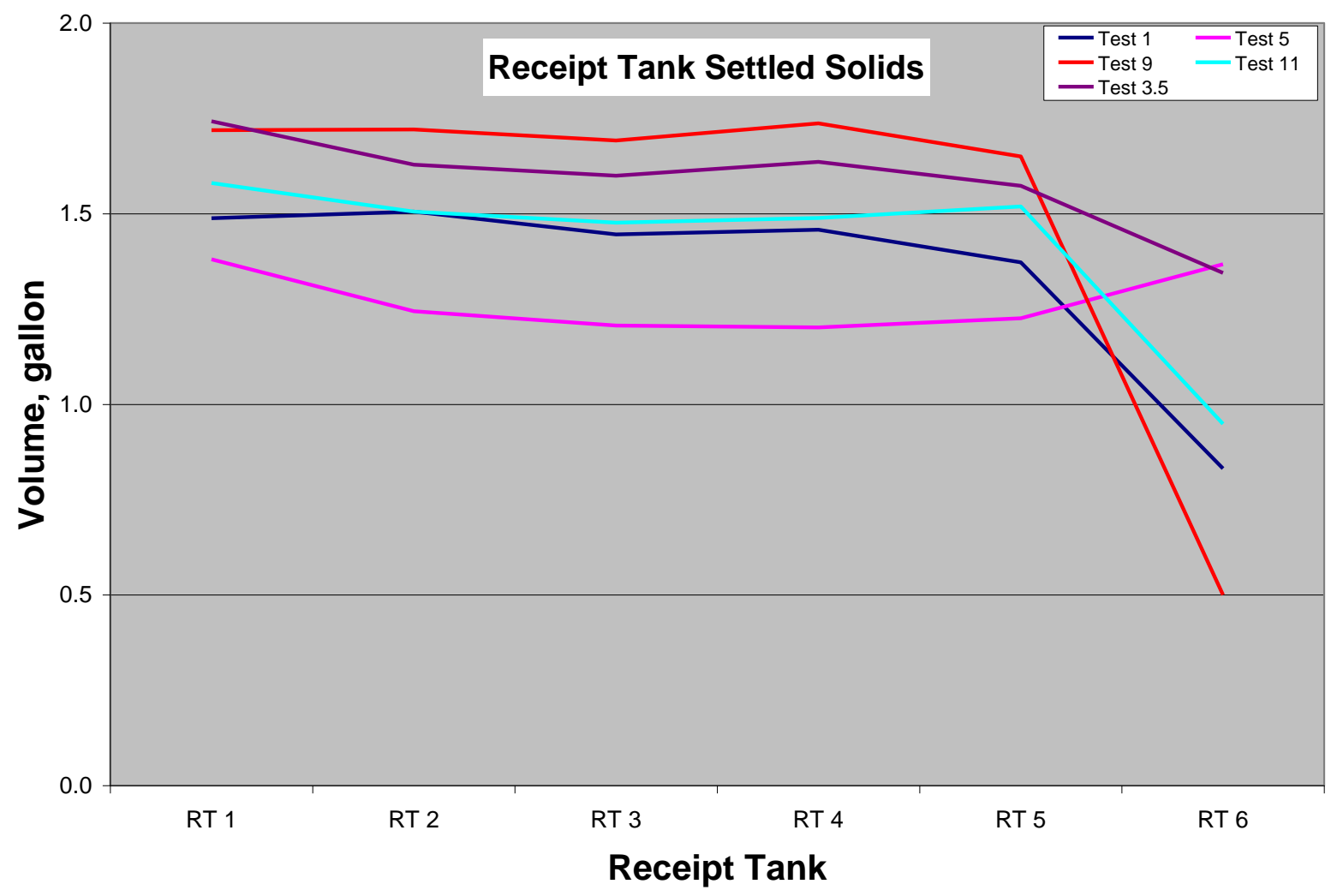

\section{Figure 12: Tests 1, 5, 9, 11 and 3.5 Volume of Total Settled Solids}

Changing a parameter in a given test may have had an impact on total solids transferred, but the plot indicates that there is essentially no impact on the solids transferred batch to batch on that particular test when the $6^{\text {th }}$ batch is neglected.

Approximately 9.5 gallons of solids were transferred in the six batches of Test 3.5, which is the highest of the five tests shown in Figure 12. The total volume of solids added to the MDT at the start of testing is approximately 10 gallons. Test 5 had the least solids transferred (indicated in Figure 12), with a total of 7.6 gallons. Although Test 5 had the least total amount of solids transferred, it showed the highest consistency batch to batch. The reduction is due to poor mixing in the MDT when the MJPs were operated at $5.0 \mathrm{gpm}$.

Visually, the best transfer of solids from the MDT to the Receipt Tanks occurred in Test 6 (Test 6 had $1.0 \mathrm{rpm}$ rotational speed and $22.4 \mathrm{ft} / \mathrm{s}$ nozzle velocity). Figure 13 is two pictures (up close) of the solids settled in the six Receipt Tanks after one day of settling. The dark material in the lower 3" clear section of the pipe is mainly the SiC. Only a small amount of solids was left in the MDT after the transfer of the $6^{\text {th }}$ batch of Test 6 . 

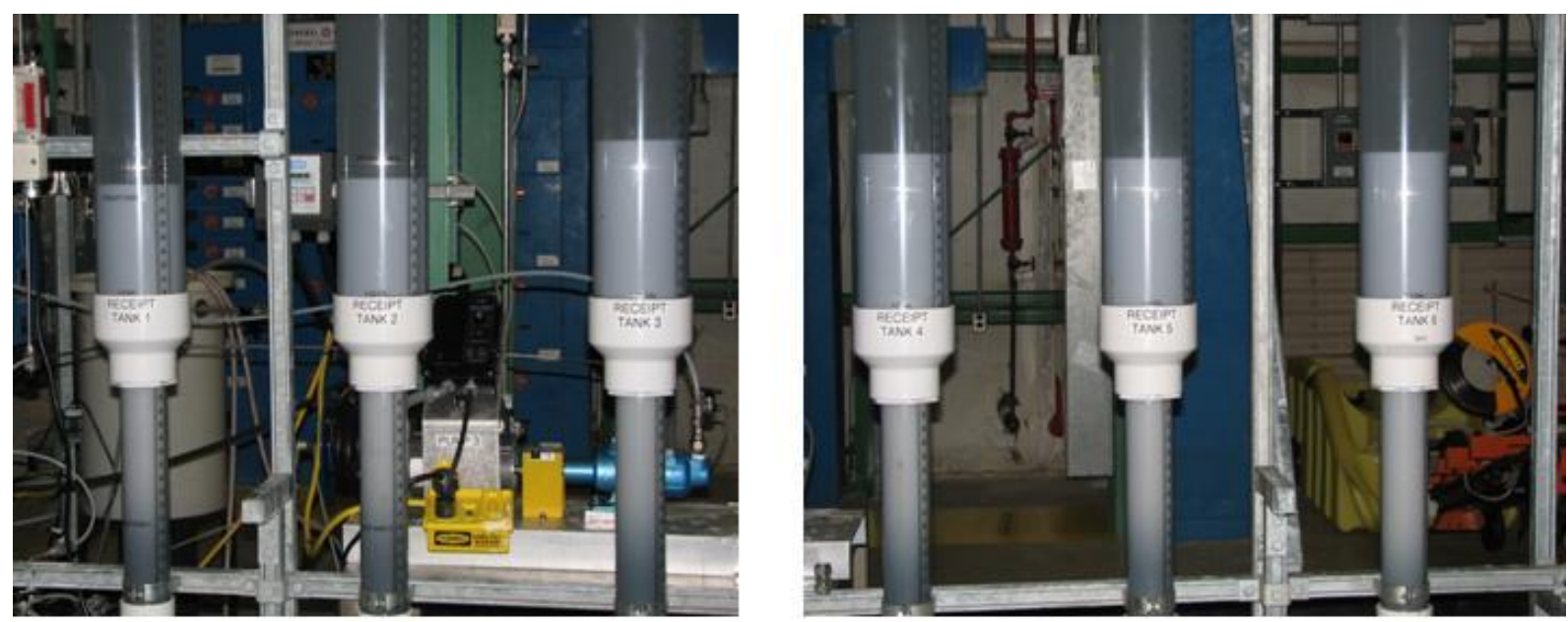

\section{Figure 13: Receipt Tank SiC Level Test 6 (1 day settling)}

Estimating the total volume of $\mathrm{SiC}$ transferred in each batch proved to be difficult. As shown in Figure 13, one can visually see that the transfer of the $\mathrm{SiC}$ in each batch was excellent and consistent (neglecting the $6^{\text {th }}$ batch). The dark material in the lower 3 " pipe is not all SiC (Gibbsite, being a smaller particle, was able to migrate a significant distance down into the $\mathrm{SiC}$, affecting the accuracy of the measurement). Thus, calculating the volume of SiC using the height of the dark material (or the data in Table 5) in the 3" pipe over-estimates the SiC in each batch. For instance the there is 15 " of $\mathrm{SiC}$ in Receipt Tank 2 which equates to a volume of 0.4 gallons. This over estimates the $\mathrm{SiC}$ by more than a factor of two.

Inspection of the MDT at the end of Test 6 found essentially no $\mathrm{SiC}$ and only gibbsite fines suspended in the $1 / 2$ " of simulant left in the tank at the end of the $6^{\text {th }}$ batch. Figure 14 gives a visual indication of how well total solids were pumped from the MDT on Test 6 (all 6 batches). 


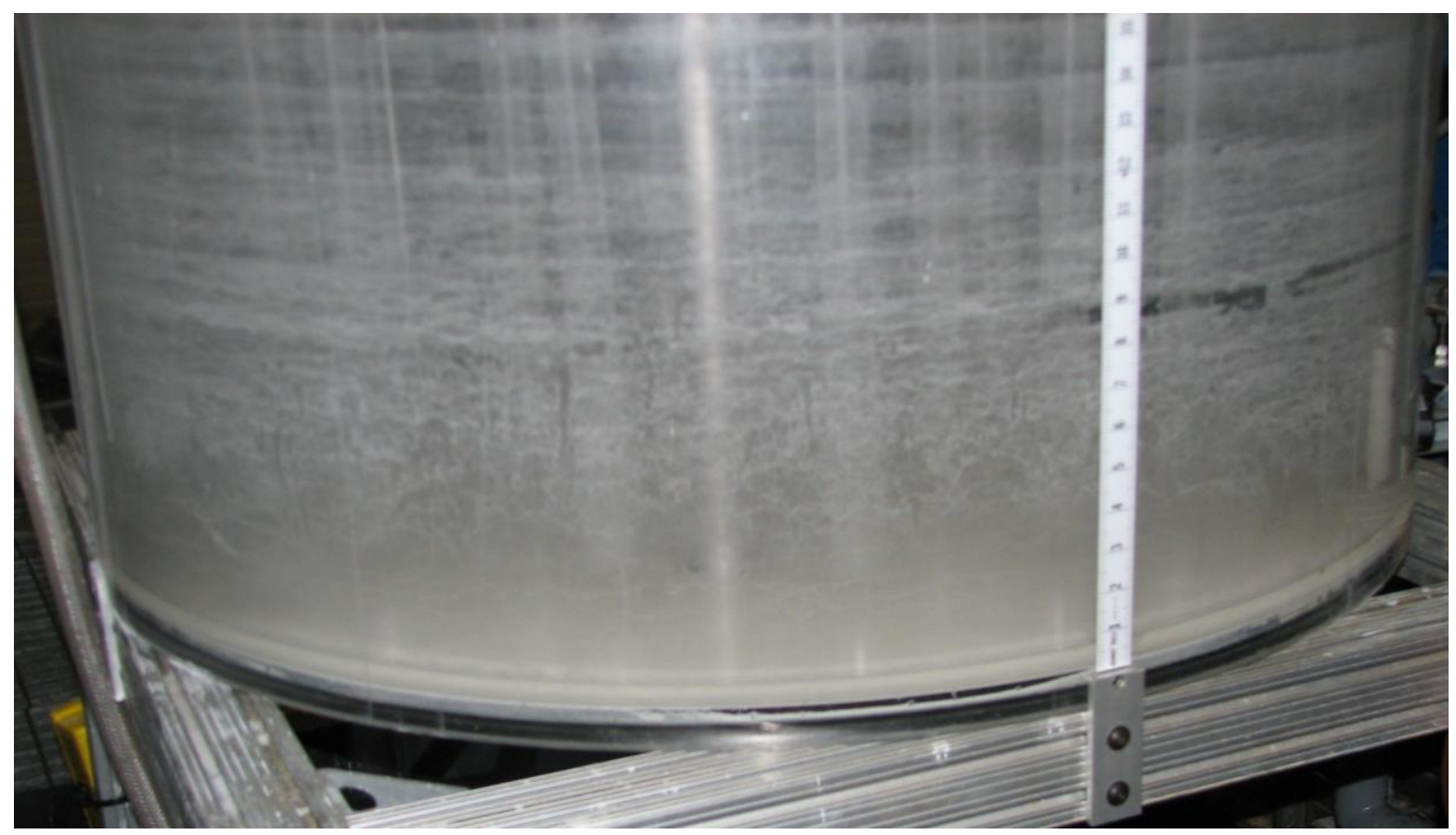

Figure 14: Solids Pumped from MDT, Test 6

The highest flow rate to the Mixing Jet Pumps was $8.0 \mathrm{gpm}$ (16 gpm total). With a total volume of 87 gallons in the $1 / 22^{\text {nd }}$ MDT, the residence time is approximately 5.5 minutes. This contrasts with the residence time of the AY-102 Tank, with 1,000,000 gallons, which is about 45 minutes with both MJPs operating. The residence time of the $1 / 22^{\text {nd }}$ scale was one of the scaling concerns from the full scale AY-102 Tank addressed in the test matrix.

\section{Particle Size Distribution (PSD)}

Samples were taken from the bottom of each the Receipt Tanks and one of the MDT dead zones at the end of Test 11 and Test 3.5. This was done to determine if the tank mixing segregated the more difficult particles from the easier particles. A sample bottle on a wire was placed standing on the bottom of each of the six Receipt Tanks before making a batch transfer. Then a batch transfer was made to each of the Receipt Tanks. The contents of the tanks were allowed to settle for 24 hours before retrieved the samples.

The sample bottles were retrieved by pulling the wire/bottle up out of the tank. A core sample was taken from the center of the solids left in one of the dead zones of the MDT.

This PSD analysis was performed to compare the particle distribution of heavy solids (SiC) left behind in the MDT to what was being transferred to the Receipt Tanks. Figure 15 is a picture of the samples retrieved from the Receipt Tanks (RT) and the MDT. 


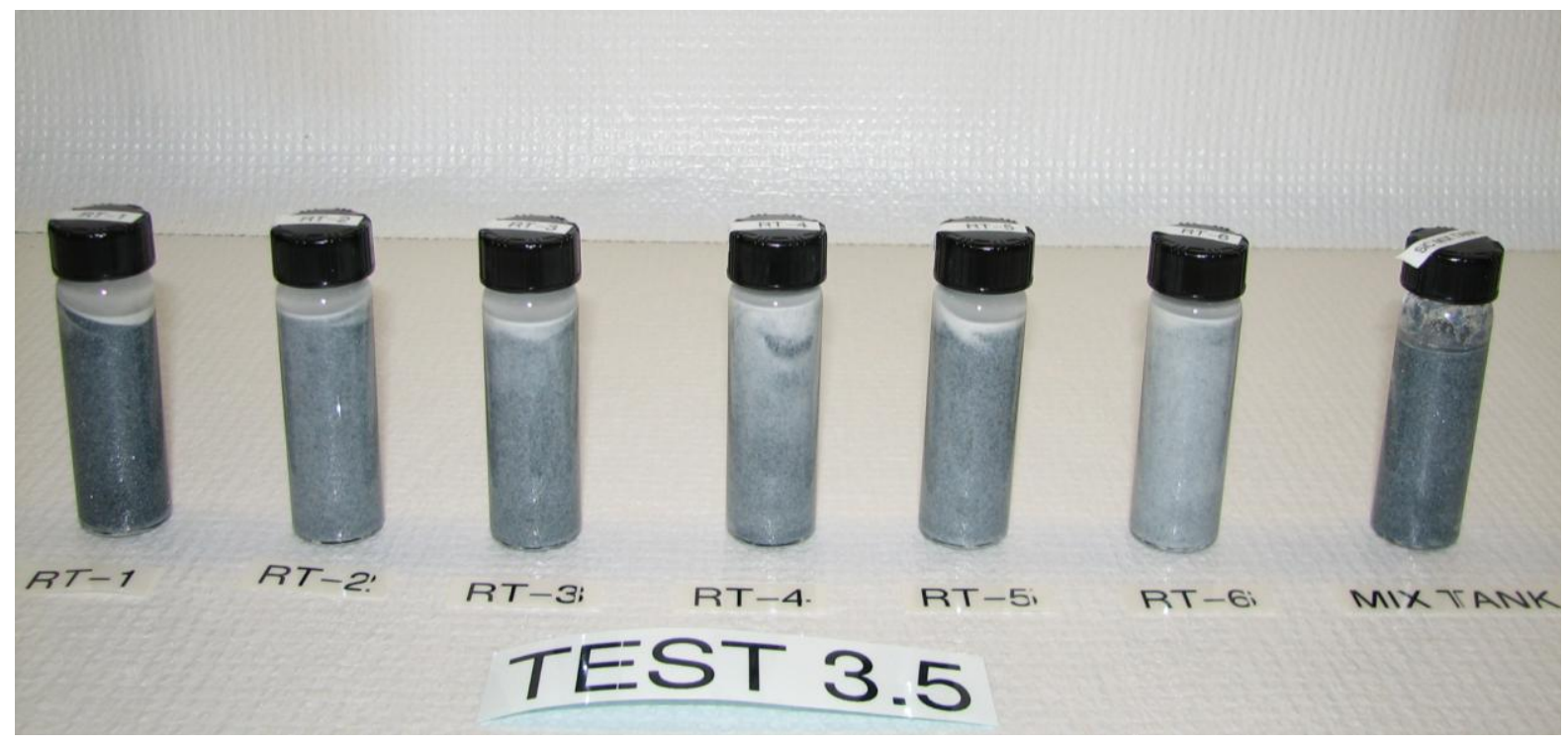

Figure 15: PSD Samples from Test 3.5, (1 day of settling)

As intended, the solids samples were taken at the bottom of the Receipt Tanks; therefore the PSD represents mostly the larger, heavier SiC particles with some embedded gibbsite particles. Samples from Receipt Tank 1, Receipt Tank 5 and the MDT were submitted for particle size distribution for both Tests 11 and 3.5. Table 8 gives the mean particle size by volume of the 6 samples analyzed.

Table 8: PSD from Test 11 and Test 3.5

\begin{tabular}{|c|c|c|c|}
\hline & $\begin{array}{c}\text { MDT } \\
\boldsymbol{\mu m}\end{array}$ & $\begin{array}{c}\text { Receipt Tank 1 } \\
\boldsymbol{\mu m}\end{array}$ & $\begin{array}{c}\text { Receipt Tank 5 } \\
\boldsymbol{\mu m}\end{array}$ \\
\hline Test 11 & 119.2 & 103.2 & 109.3 \\
\hline Test 3.5 & 126.3 & 150.1 & 117 \\
\hline
\end{tabular}

Detailed information of the PSD analysis is given in Appendix C.

The PSD data suggests that the particle size distribution in the tank remains consistent between batches and the solids left in the tank. 


\subsection{CONCLUSIONS}

- For the twelve test conducted, the solids (gibbsite and $\mathrm{SiC}$ ) transferred were consistent for the first five batches transferred regardless of mixing or batch transfer conditions.

- The poor consistency of the solids transferred in batch 6 was due to low liquid level in the MDT, and thus poor solids distribution throughout the volume of liquid remaining on the tank.

- At a flow rate of $8.0 \mathrm{gpm}\left(22.4 \mathrm{ft} / \mathrm{s}\right.$ per nozzle, $\left.\mathrm{U}_{\mathrm{o}} \mathrm{D}=0.504 \mathrm{ft}^{2} / \mathrm{s}\right)$ to each MJP the contents of the MDT were well mixed and the solid particles effectively suspended.

- At $5.0 \mathrm{gpm}\left(14.0 \mathrm{ft} / \mathrm{s}\right.$ per nozzle, $\mathrm{U}_{\mathrm{o}} \mathrm{D}=0.315 \mathrm{ft}^{2} / \mathrm{s}$ ) to each Mixing Jet Pump, solids (mainly $\mathrm{SiC}$ ) deposited out in the Mixer Tank, creating two large dead zones in the MDT (see Tests 5 \& 10).

- The large, dark SiC particles, that normally fell out to the tank bottom immediately, transferred well when the MJP was operated at $8.0 \mathrm{gpm}$, rotating at $1.0 \mathrm{rpm}$. This suggests that that the rotational speed of the pumps plays a role in the homogeneity and suspension of particles in the MDT, and hence the consistent transfer of solids.

- As the liquid level dropped in the MDT, mixing of the solids in the tank became less effective and areas of solids accumulation (dead zones) began to appear.

- Relocating the height of transfer line suction point in the MDT (Test 4 \& 9) did not impact the consistency of total solids transferred from batch to batch. This phenomenon was demonstrated whether the transfer pump was in the center or near the wall of the tank. Visual inspections suggest that the higher suction position is less effective in transferring the heavy solids ( $\mathrm{SiC})$ in batches 5 and 6.

- The two batch transfer flow rates tested had little or no impact on the consistency between the batch transfers to the Receipt Tanks, because the transfer pump provided the velocity that was needed to lift the particles and prevent them from settling in the transfer lines.

- Changing a parameter may have had a small impact on total solids transferred from the MDT on a given test, but the data indicates that there is essentially no impact on the solids transferred batch to batch, barring the $6^{\text {th }}$ batch.

- The particle size distribution analysis indicate that the larger more dense particles remains consistent between transfer batches and the remaining piles of accumulated solids.

- Visual inspections suggest that the nozzle positions (i.e., the synchronous phase angle) between the two MJPs may have an impact on how well a tank mixes. 


\subsection{REFERENCES}

1 Adamson, D. J., M. R. Poirier, T. J. Steeper, "Demonstration of Internal Structures Impacts on Double Shell Tank Mixing Effectiveness", SRNL-STI-2009-00326, April, 2009

2 Adamson, D. J., Poirier, M. R., Task Technical \& QA Plan, "Demonstration of Simulated Waste Transfers from Tank AY-102 to the Hanford Waste Treatment Facility”, SRNL-L3100-2009-00181, July 2009

3 Tank Farm Mixing Demonstration Planning Workshop, RPT-1741-0001, June, 2009 


\title{
APPENDIX A: R \& D DIRECTION FOR DEMONSTRATION OF SIMULATED WASTE TRANSFERS FROM TANK AY-102 TO THE HANFORD WASTE TREATMENT FACILITY
}

\author{
SAVANNAH RIVER NATIONAL LABORATORY \\ ENGINEERING DEVELOPMENT LABORATORY
}

Research and Development Direction

Title: Demonstration of Simulated Waste Transfers

From Tank AY-102 To The Hanford Waste

Treatment Facility

Page:1 of 13

Approved by:

Preparer

Date

Technical Reviewer

Date

EDL Manager

Date

1.0

PURPOSE

As part of the TTQAP [6.1] for "Demonstration of the Waste Transfers from Double Shell Tank AY-102 to WTP", this R\&D Direction will demonstrate the effectiveness of mixing in the AY-102 tank using a pilot scale tank system with the obstruction installed. Simulant will be used to simulant the waste in the AY-102 Tank. This Direction shall be appended to the final report for permanent documentation.

SCOPE

This R\&D directions, developed under the guidance of SRNL Conduct of R\&D [6.2] and of Procedure L1 [6.3], applies only to the setting up, testing, and dismantling of the AY-102 Tank Mixing and Transfer Demonstration System. The testing will be conducted in the Engineering Development Laboratory (EDL), SRS Bldg. 786-A. To satisfy the TTQAP, a $1 / 22^{\text {nd }}$ scaled Mixing Tank and transfer systems was designed and constructed. Six (6) Receipt Tanks will be used to receive the transfer and obtain an accurate measurement of the solids transferred.

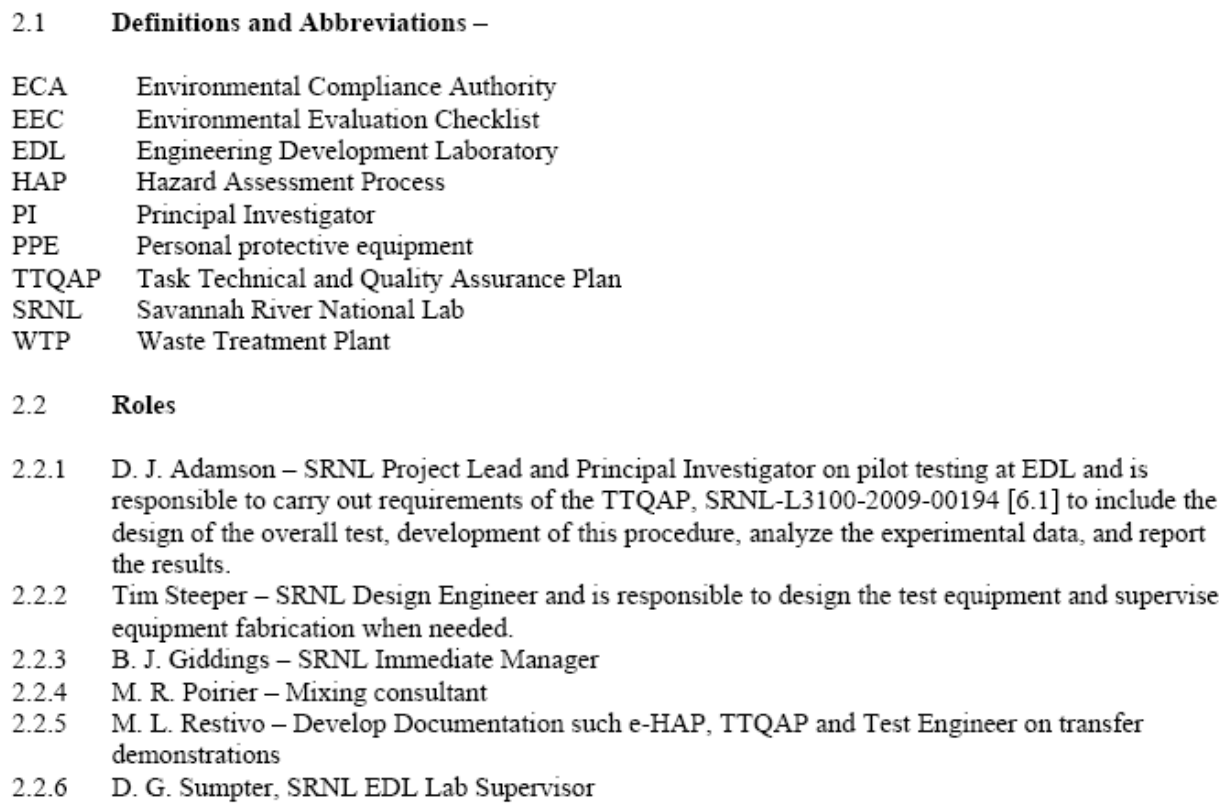


SAVANNAH RIVER NATIONAL LABORATORY

ENGINEERING DEVELOPMENT LABORATORY

Research and Development Direction

Title: Demonstration of Simulated Waste Transfers

From Tank AY-102 To The Hanford Waste

Treatment Facility

Page:2 of 13

\subsection{PRECAUTIONS/LIMITATIONS}

All SRNL personnel located at the test site shall follow all safety rules and requirements of the Engineering Development Laboratory.

- Personnel shall have SRNL Laboratory Standard Training.

- The appropriate PPE shall be used at all times.

- During charging the mixing tank with simulant, a minimum of a lab coat, face shield or goggles, chemical resistance or nitrile gloves, and apron shall be donned.

- During the demonstration safety glasses and lab coat shall be worn within the secondary containment.

- Before transferring simulant to the Receipt Tank, the HAP will be revised.

- The process involves overhead transfer line with caustic simulant under pressure; do not loiter under the batch tanks or around the piping. A barricade will be established to keep observers away from the hazard.

\section{PREREQUISITE ACTIONS}

Note: As discussed in the approved EEC, the simulant will not be disposed of at the end of the mixing demonstration. The only disposition of materials will be for the solid materials used during testing. Only the solids will be disposed of. The simulant may be used for additional testing within SRNL. For hazards identification of the simulant, see Appendix A2.

\subsection{Simulant Preparation}

The simulant for this task was mixed with the solids (gibbsite and Silicon Carbide) during the Mixing Demonstration and is ready for testing. The same simulant will be used for these transfer demonstrations that was used for the previous mixing demonstrations. Process water will be used to make up for evaporation.

\subsection{Calibrations}

Instrumentation will be calibrated before and after testing using site standards.

\section{$4.3 \quad$ Training}

During shakedown with water on the test system, the PI and/or Test Engineer will provide training of the R\&D Directions.

5.1 Shakedown of AY-102 Transfer Demonstration, Transferring water into the Receipt Tank

Note: the items shown below can be done in any order as directed by PI

- Shakedown of AY-102 Tank Transfer Demonstration will be conducted with process water.

- Record information in Lab notebook

- The AY-102 Mixing Tank will not be used in the water Shakedown.

- A temporary 55 gallon drum or a small tank will be used to make water transfer into the Receipt Tanks. 


\section{SAVANNAH RIVER NATIONAL LABORATORY \\ ENGINEERING DEVELOPMENT LABORATORY}

Research and Development Direction

Title: Demonstration of Simulated Waste Transfers

From Tank AY-102 To The Hanford Waste

1. Ensure drum or tank is clean.

2. Fill temporary tank with process water, see schematic of test assembly in Appendix A1.

3. Install Transfer Line Mockup Line into the temporary tank, approximately $1 / 4$ " from the bottom.

4. Make transfer into Receipt Tank 1 by opening/ensuring open V7 to batch tanks and V11 to tank 1 .

5. Turns on Pump 3 and set the flow to $2.9 \mathrm{gpm}$ or $5.8 \mathrm{gpm}$ per the Test Engineer.

6. Pump 14.3 gallons in to Receipt Tank 1 and turn off pump.

7. Check for leaks in tank, piping and system components.

8. Repair any leaks.

9. Repeat steps 4 through 8 as directed by PI.

10. When Filling is complete, close valve V11.

11. For Filling and checking Batch Tanks $2-6$ use the following valves in place of V11 and repeat steps 4 through 11 for the associated tank:

\begin{tabular}{|c|c|}
\hline Tank Number & Inlet Valve \\
\hline 2 & V21 \\
\hline 3 & V31 \\
\hline 4 & V41 \\
\hline 5 & V51 \\
\hline 6 & V61 \\
\hline
\end{tabular}

5.2 Shakedown of AY-102 Transfer Demonstration, Transferring water out of the Receipt Tank

1. Ensure Air is available to header supplying purge air to batch tanks.

2. Ensure Batch Receipt Tanks $1-6$ are filled with water to the appropriate level as directed by the PI.

3. Turn on air sparger to the six receipt tanks via opening V13, V23, V33, V43, V53, V63 and V9 to inspect the mixing in each tank. (Note: the valves may need to be throttled due to excess air mixing).

4. At the direction of the Lab Supervisor the process water in all six tanks may be pumped to the drain or back into the temporary tank.

5. To transfer from Receipt Tank 1, close V13 and open V12.

6. Turn on Pump 2 to pump water out of tank.

7. Turn Pump 2 off.

8. Transfer from Receipt Tank 2, close V23 and open V22.

9. Turn on Pump 2 to pump water out of tank.

10. Turn Pump 2 off.

11. Transfer from Receipt Tank 3, close V33 and open V32.

12. Turn on Pump 2 to pump water out of tank.

13. Turn Pump 2 off.

14. Transfer from Receipt Tank 4, close V43 and open V42.

15. Turn on Pump 2 to pump water out of tank.

16. Turn Pump 2 off.

17. Transfer from Receipt Tank 5, close V53 and open V52.

18. Turn on Pump 2 to pump water out of tank.

19. Turn Pump 2 off.

20. Transfer from Receipt Tank 6, close V63 and open V62.

21. Turn on Pump 2 to pump water out of tank.

22. Turn Pump 2 off.

23. The shakedown with process water may be repeated if deemed necessary by the PI or Test Engineer. 
SAVANNAH RIVER NATIONAL LABORATORY

ENGINEERING DEVELOPMENT LABORATORY

Research and Development Direction

Title: Demonstration of Simulated Waste Transfers

From Tank AY-102 To The Hanford Waste

Treatment Facility

Page: 4 of 13

24. Drain as much water from the Receipt Tanks and lines as practical before testing with simulant.

\subsection{Transferring from Mixing Tank}

As shown in Table 1 There will be a total of twelve (12) different transfer demonstrations from the AY102 Mixing Tank with the obstructions installed. The twelve demonstrations are in the order they will be conducted. Each demonstration will be conducted using the same 87 gallons (15.6") of simulant that was used in the Mixing Tank demonstration.

Table 1: Test Matrix for Transfer Demonstrations

\begin{tabular}{|c|c|c|c|c|c|c|}
\hline \multirow{2}{*}{$\begin{array}{c}\text { Test } \\
\#\end{array}$} & \multirow{2}{*}{$\begin{array}{l}\text { Location of } \\
\text { Transfer } \\
\text { pump in } \\
\text { tank }\end{array}$} & \multirow[t]{2}{*}{ Transfer Type } & \multirow{2}{*}{$\begin{array}{c}\text { Elevation } \\
\text { of Transfer } \\
\text { Pump } \\
\text { suction } \\
\text { (inches) }\end{array}$} & \multirow{2}{*}{$\begin{array}{c}\text { Transfer } \\
\text { from } \\
\text { Mixing } \\
\text { Tank } \\
\text { (gpm) }\end{array}$} & \multicolumn{2}{|c|}{ Mixer Jet pumps } \\
\hline & & & & & $\begin{array}{c}\text { Rotation } \\
\text { (rpm) }\end{array}$ & $\begin{array}{c}\text { Flowrate } \\
\text { (gpm) }\end{array}$ \\
\hline 1 & 1 (baseline) & Batch (6 days) & 0.25 & 0.29 & 4.4 & 8.0 \\
\hline 2 & 1 (baseline) & Semi-continuous & 0.25 & 0.29 & 4.4 & 8.0 \\
\hline 3 & 1 (baseline) & Semi-continuous & 0.25 & 0.58 & 4.4 & 8.0 \\
\hline 3.5 & \multicolumn{6}{|c|}{ Duplicate Test 3 to demonstrate repeatability of data } \\
\hline 4 & 1 (baseline) & Semi-continuous & $2.0 \quad(8 X)$ & 0.58 & 4.4 & 8.0 \\
\hline 5 & 1 (baseline) & Semi-continuous & 0.25 & 0.58 & 4.4 & 5.0 \\
\hline 6 & 1 (baseline) & Semi-continuous & 0.25 & 0.58 & $1.0(5 \mathrm{X})$ & 8.0 \\
\hline 7 & 3 (riser \# 1) & Semi-continuous & 0.25 & 0.58 & 4.4 & 8.0 \\
\hline 8 & 3 (riser \# 1) & Semi-continuous & 0.25 & 0.58 & $1.0(5 \mathrm{X})$ & 8.0 \\
\hline 9 & 3 (riser \# 1) & Semi-continuous & $2.0 \quad(8 \mathrm{X})$ & 0.58 & 4.4 & 8.0 \\
\hline 10 & 3 (riser \# 1) & Semi-continuous & 0.25 & 0.58 & 4.4 & 5.0 \\
\hline 11 & 3 (riser \# 1) & Semi-continuous & 0.25 & 0.29 & 4.4 & 8.0 \\
\hline
\end{tabular}

** The flow rate to Mixer Jets Pumps will be varied from $8.0 \mathrm{gpm}$ to $5 \mathrm{gpm}$

\subsubsection{Test 1 from Table 1, This transfer will tank 6 days to make}

5.3.1.1 Insure there is $15.6^{\prime \prime}$ of simulant in the mixing tank.

5.3.1.2 Have cameras set up to film the transfer demonstration.

5.3.1.3 Turn on bearing cooling water to seal water pump.

5.3.1.4 Turn on jet rotation drive motors. Jets will rotate at $4.4 \mathrm{rpm}$.

5.3.1.4.1 Turn on video camera as directed by PI 


\section{SAVANNAH RIVER NATIONAL LABORATORY \\ ENGINEERING DEVELOPMENT LABORATORY \\ Research and Development Direction}

Title: Demonstration of Simulated Waste Transfers

From Tank AY-102 To The Hanford Waste

Treatment Facility

Page:5 of 13

5.3.1.5 Slowly increase the flow rate through each Mixer Jet Pump until $8.0 \mathrm{gpm}$ is flowing through each pump. The residence time for the tank is 5.4 minutes at this flow rate.

5.3.1.6 Allow the contents of the Mixing Tank to mix for 30 minutes ( $6 \mathrm{X}$ the residence time) before transferring to Receipt Tank.
$5.3 .1 \cdot 6.1$
Record start time
$5.3 \cdot 1.6 .2$
Record stop time

5.3.1.7 Ensure the following valves are closed: V11, V21, V31, V41, V51 and V61

5.3.1.8 Adjust V7 to direct flow from Pump 3 to Receipt Tanks and V11 to make the first transfer to Receipt Tank 1 .

5.3.1.9 Turn on Pump 3 and set the transfer rate at $0.29 \mathrm{gpm}$. The Mixer Jet Pumps will continue to operate during the transfer to Receipt Tank 1

5.3.1.10 Pump 14.3 gallons of simulant into Receipt Tank 1. The transfer will take approximately 49.5 minutes.

5.3.1.11 Turn off video.

5.3.1.12 Turn off Pump 3 and purge the Flow 3 meter line with air by positioning V7 to direct air sparging towards receipt tanks and opening V8

5.3.1.13 Close V8 and V11, and return V7 to direct simulant to receipt tanks.

5.3.1.14 Slowly back down the speed of Mixer Jet Pumps and turn off.

5.3.1.15 Turn off Bearing cooling water.

5.3.1.16 At the direction of the PI the contents of the Receipt Tank 1 may be sparged by opening V9 and gently opening V13. This will allow for better separation of the large and small particles when settled in the Receipt Tank.

5.3.1.17 Allow contents of the Mixing Tank to settle overnight before making a transfer to the next Receipt Tank.

5.3.1.18 On the following morning, take measurements of the $\mathrm{SiC}$ (dark particles) and the gibbsite (cream colored particles) settles to the bottom of the Receipt Tank.

5.3.1.18.1 Take photos and video as directed by PI.

Repeat 5.3.1.1 through 5.3.1.18.1 for transferring to Receipt Tank $2-6$. Refer to The schematic drawing of the test system in appendix A1 for valve line up when transferring to Receipt Tank $2-6$ 


\section{SAVANNAH RIVER NATIONAL LABORATORY ENGINEERING DEVELOPMENT LABORATORY}

Research and Development Direction

Title: Demonstration of Simulated Waste Transfers

From Tank AY-102 To The Hanford Waste

Treatment Facility
Page: 6 of 13

5.3.2 Transferring from Receipt Tanks back to the Mixing Tank. This section will be used for transferring from the Receipt Tanks for all twelve tests in the Test Matrix.

5.3.2.1 Sparge into the Receipt Tanks $1-6$ by opening V9, V13, V23, V33, V43, V53 and V63. Continue sparging until settled solids are mixed into solution before transferring back to Mixing Tank.

5.3.2.2 To start transfer from the six Receipt Tanks open V12, V22, V32, V42, V52 \& V62 and start Pump 2.

5.3.2.3 Turn off Pump 2 and close V12, V22, V32, V42, V52 \& V62.

Note: if deemed necessary by the PI because of solids settling out, the transfer from the Receipt Tanks back to the Mixing Tank may carry out one Receipt Tank at a time.

5.3.2.4 Close air supply valves to spargers V9, V13, V23, V33, V43, V53 and V63.

5.3.2.5 If significant amounts of solids have been left behind in the Receipt Tanks, rinse the tanks with a small amount of supernate from the Mixing Tank. Sparge the Receipt Tanks if determined necessary by the Test Engineer.

5.3.2.6 Transfer solution back to the Mixing Tank via open V12, V22, V32, V42, V52 \& V62 and start Pump 2.

5.3.2.7 Turn off Pump 2 and close V12, V22, V32, V42, V52 \& V62.

5.3.2.8 Repeat 5.3.2.5 through 5.3.2.7 if deemed necessary by the Test Engineer.

5.3.2.9 Continue to next test in section 5.3.3.

5.3.3 Tests 2 through Test 11 from Table 1 are semi-continuous and will take one day to make the 6 individual transfers from the Mixing Tank.

5.3.3.1 Insure there is 15.6 " of simulant in the mixing tank.

5.3.3.2 Have cameras set up to film the transfer demonstration.

5.3.3.3 Turn on bearing cooling water to seal water pump.

5.3.3.4 Turn on jet rotation drive motors. Jets will rotate at $\mathrm{rpm}$ as specified in Test Matrix.

5.3.3.4.1 Turn on video as directed by PI. 


\section{SAVANNAH RIVER NATIONAL LABORATORY \\ ENGINEERING DEVELOPMENT LABORATORY \\ Research and Development Direction}

Title: Demonstration of Simulated Waste Transfers

From Tank AY-102 To The Hanford Waste

Page:7 of 13

5.3.3.5 Slowly increase the flow rate through each Mixer Jet Pump until gpm as specified in Test Matrix is flowing through each pump. The residence time for the tank is 5.4 minutes at $8.0 \mathrm{gpm}$ flow rate and 8.6 minutes at $5.0 \mathrm{gpm}$.

5.3.3.6 On the initial startup of each test, allow the contents of the Mixing Tank to mix for 30 minutes at $8.0 \mathrm{gpm}$ flow rate (50 minutes at $8.0 \mathrm{gpm}$ flow rate) to each Mixer Jet Pump before transferring to Receipt Tank.

Note: Mixer Jet Pump will not be turned off after each batch transfer on Test 2 through Test 11.

5.3.3.7 Open V11 and direct V7 to make the first transfer to Receipt Tank 1.

5.3.3.8 Turn on Pump 3 and set the transfer rate at $0.29 \mathrm{gpm}$ or $0.58 \mathrm{gpm}$ as specified in the test matrix. The Mixer Jet Pumps will continue to operate during the transfer to Receipt Tank 1.

5.3.3.9 Pump 14.3 gallons of simulant into Receipt Tank 1. The transfer will take approximately 49.5 minutes ( 24.7 minutes at $0.58 \mathrm{gpm}$ ).

5.3.3.10 Turn off Pump 3, close V11.

Repeat 5.3.3.1 through 5.3.3.10 to transfer to Receipt Tank 2 through Receipt Tank 6. When the Mixing Tank level drops to a low liquid level such as in the $5^{\text {th }}$ or $6^{\text {th }}$ transfer, the flow rate to the Mixer Jet Pumps may require less flow. At the direction of the Test Engineer, turn down the flow rate to the Mixer Jet Pump to a point that does not impact the transfer. Record the adjustment made to the Mixer Jet Pumps in the Lab Notebook.

5.3.3.11 To empty the six Receipt Tanks return to 5.3.2

5.3.3.12 Complete Test 3 of the Test Matrix, follow 5.3.3.1 through 5.3.3.11. Ensure test parameters of the Test Matrix are being used for Test 3.

5.3.3.13 Complete Test 3.5 of the Test Matrix, follow 5.3.3.1 through 5.3.3.11. Ensure test parameters of the Test Matrix are being used for Test 3.5.

5.3.3.14 Complete Test 4 of the Test Matrix, follow 5.3.3.1 through 5.3.3.11. Ensure test parameters of the Test Matrix are being used for Test 4 .

5.3.3.15 Complete Test 5 of the Test Matrix, follow 5.3.3.1 through 5.3.3.11. Ensure test parameters of the Test Matrix are being used for Test 5 .

5.3.3.16 Complete Test 6 of the Test Matrix, follow 5.3.3.1 through 5.3.3.11. Ensure test parameters of the Test Matrix are being used for Test 6 .

5.3.3.17 Complete Test 7 of the Test Matrix, follow 5.3.3.1 through 5.3.3.11. Ensure test parameters of the Test Matrix are being used for Test 7 .

5.3.3.18 Complete Test 8 of the Test Matrix, follow 5.3.3.1 through 5.3.3.11. Ensure test parameters of the Test Matrix are being used for Test 8 . 
SAVANNAH RIVER NATIONAL LABORATORY

ENGINEERING DEVELOPMENT LABORATORY

Research and Development Direction

Title: Demonstration of Simulated Waste Transfers

From Tank AY-102 To The Hanford Waste

Treatment Facility

Page: 8 of 13

5.3.3.19 Complete Test 9 of the Test Matrix, follow 5.3.3.1 through 5.3.3.11. Ensure test parameters of the Test Matrix are being used for Test 9 .

5.3.3.20 Complete Test 10 of the Test Matrix, follow 5.3.3.1 through 5.3.3.11. Ensure test parameters of the Test Matrix are being used for Test 10 .

5.3.3.21 Complete Test 11 of the Test Matrix, follow 5.3.3.1 through 5.3.3.11. Ensure test parameters of the Test Matrix are being used for Test 11 .

At the direction of the SRNL PI test may be repeated or additional test with other parameters may be conducted by following 5.3.3. 
SRNL-STI-2009-00717

SAVANNAH RIVER NATIONAL LABORATORY

ENGINEERING DEVELOPMENT LABORATORY

Research and Development Direction

Title: Demonstration of Simulated Waste Transfers

From Tank AY-102 To The Hanford Waste

Treatment Facility

Page:9 of 13

6.0 REFERENCE:

6.1 Adamson, D. J., Poirier, M. R., Restivo, M. L., Task Technical \& Quality Assurance Plan, "Demonstration of Simulated Waste Transfers From Tank AY-102 to the Hanford Waste Treatment Facility" Document No. : SRNL-L3100-2009-00194, Rev. 0, July, 2009.

6.2 Conduct of Research \& Development: Integrated Safety Management for the R\&D Environment, Document No. WSRC-IM-97-00024, Rev. 3.3, January 25, 2007.

6.3 SRNL Procedural Manual L1, April 25, 2007. Task Notebook, "Demonstration of the Internal Structures Impacts on AY-102 Tank Mixing Effectiveness" Document No. SRNL-NB-2009-00014, February, 2009. 
SAVANNAH RIVER NATIONAL LABORATORY

ENGINEERING DEVELOPMENT LABORATORY

Research and Development Direction

Title: Demonstration of Simulated Waste Transfers

From Tank AY-102 To The Hanford Waste

Treatment Facility

Page: 10 of 13

Appendices

Appendix Al: Schematic of Scaled AY-102 Transfer Demonstration

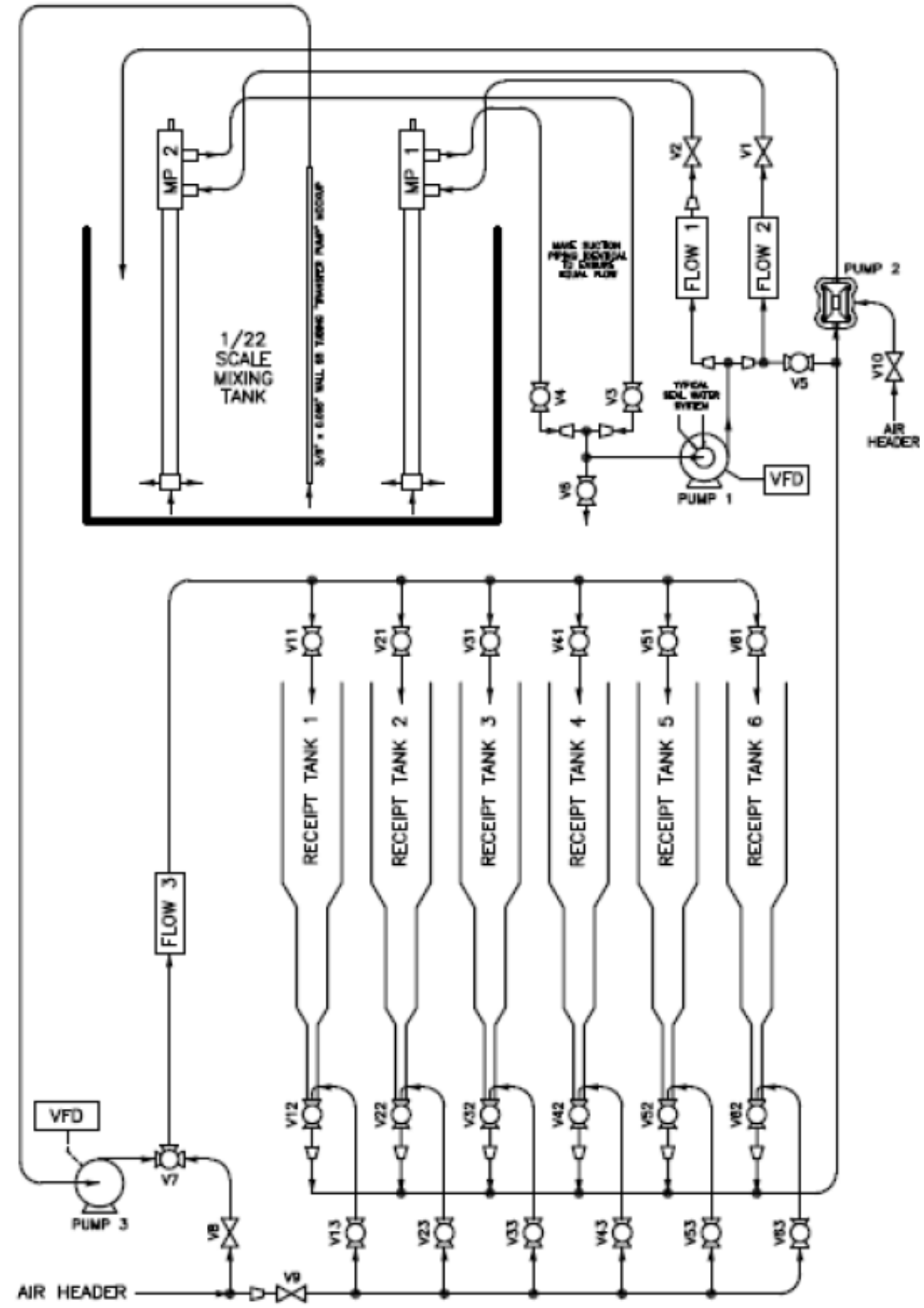

Page 39 
Title: Demonstration of Simulated Waste Transfers

From Tank AY-102 To The Hanford Waste

Appendix A2: Chemical Hazard Identification Summary

\begin{tabular}{|c|c|c|c|c|c|c|c|c|c|c|c|}
\hline 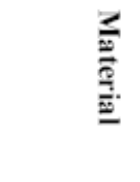 & 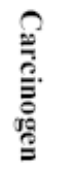 & $\frac{\rho}{0}$ & $\begin{array}{l}\frac{T}{2} \\
\frac{2}{0} \\
\frac{0}{0} \\
\frac{a}{2} \\
\frac{1}{2}\end{array}$ & 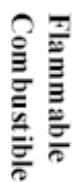 & $\stackrel{\theta}{*}$ & 音. & 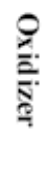 & $\begin{array}{l}\overline{0} \\
\stackrel{0}{*} \\
\stackrel{0}{=}\end{array}$ & 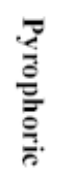 & 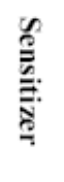 & 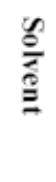 \\
\hline $\begin{array}{l}\text { Test } \\
\text { Simulant }\end{array}$ & & $\mathrm{X}$ & & & & & & & & & \\
\hline & & & & & & & & & & & \\
\hline
\end{tabular}

\section{HAZARDOUS MATERIAL IDENTIFICATION}

Carcinogen - substance capable of causing or producing cancer

- Types of carcinogens: Asbestos, vinyl chloride, cadmium, benzene, formaldehyde

- Routes of entry: Inhalation, ingestion absorption, injection

- Signs and symptoms of exposure: Usually latent affects include anemia, tumors or lesions, weight loss, body abnormalities

- Target organs: Different carcinogens affect different organs. MSDS should be referenced for each material.

Corrosives - any chemical that will attack and destroy any living tissue it physically contacts

- Types of corrosives: Acids such as sulfuric, hydrochloric, perchloric, chromic and nitric. Caustics such as lime, lye (sodium hydroxide), phosphates, and chromates

- Routes of entry: Absorption, inhalation, ingestion, injection

- Signs and symptoms of exposure: Burns, destruction of tissue, dry and cracking skin. Note: Depending on exposure, these hazards can be internal and external.

- Target organs: Primarily skin, but can affect the eyes, stomach, lungs, and respiratory system.

Explosives - any material that causes a sudden (almost instantaneous) release of pressure, gas and heat when subjected to sudden shock, pressure, or high temperature

- Types of explosives: nitroglycerin, aged picric acid, aged ether, TNT

- Routes of entry: Injection, ingestion, inhalation, absorption

- Signs and symptoms of exposure: Hazards expected form accidental explosions include intense heat and light, shattering force, fire, powerful blast impacts, and fragments or projectiles 
SAVANNAH RIVER NATIONAL LABORATORY

ENGINEERING DEVELOPMENT LABORATORY

Research and Development Direction

Title: Demonstration of Simulated Waste Transfers

From Tank AY-102 To The Hanford Waste

Treatment Facility

Page:12 of 13

- Target organs: Any part of the body is susceptible to damage from an explosive

Flammables and Combustibles - Any material that can ignite or produce a flame. Flammables have a flash point below $100^{\circ} \mathrm{F}$. Combustibles have a flash point at or above $100^{\circ} \mathrm{F}$.

- Types of flammables: Benzene, butane, toluene, gasoline,

- Types of combustibles: Phenol, diesel

- Routes of entry: Ingestion, inhalation, absorption, injection

- Signs and symptoms of exposure: Burns or blisters

- Target organs: Any part of the body is susceptible to damage from an explosive

Gases - a phase of matter in which the substance expands readily to fill any containing vessel. Gas has no definite volume or shape.

- Types of gases: There are four categories of gases: poisonous, flammable, irritant, and asphyxiate. Types of gases include chlorine, fluorine, hydrogen sulfide, sulfur dioxide, acetylene, butane, ethylene, ethane, methane, and propane.

- Routes of entry: Absorption through mucous membranes, eyes, skin; inhalation of toxic vapors

- Signs and symptoms of exposure: Dizziness, headache, nausea, watery eyes, difficulty breathing, frostbite

- Target organs: Lungs, skin, eyes, respiratory system

Irritants - a chemical that can cause inflammation at the point of contact.

- Types of irritants: Ammonia, fibrous glass, fine meal dusts, alcohol, solvents, and detergents

- Routes of entry: Absorption, inhalation, injection, ingestion

- Signs and symptoms of exposure: Skin, eye, and mucous membrane irritation; dermatitis; coughing; itching

- Target organs: Upper respiratory tract, eyes, skin, lungs, mouth, nose

Oxidizers - any material that can supply oxygen to start or support a fire.

- Types of oxidizers: Nitrates, hydrogen peroxide, chlorate, chlorine gas, perchloric acid

- Routes of entry: Absorption, inhalation, ingestion, injection

- Signs and symptoms of exposure: Internal and external burns and blisters

- Target organs: Skin, eyes, lungs, mucous membranes

Poisons - Substances that may cause death or serious injury if swallowed, inhaled or come in contact with the skin.

- Types of poisons: Carbon monoxide, dieldrin, arsenic pentoxide, chlorine, methylene dichloride, cyclohexanone, cyanide

- Routes of entry: Absorption, inhalation, injection, ingestion 


\title{
SAVANNAH RIVER NATIONAL LABORATORY \\ ENGINEERING DEVELOPMENT LABORATORY \\ Research and Development Direction
}

Title: Demonstration of Simulated Waste Transfers

From Tank AY-102 To The Hanford Waste

Treatment Facility

\author{
Page: 13 of 13
}

- Signs and symptoms of exposure: Coughing, difficulty breathing, skin rash, eye irritation, unconsciousness, light-headedness, shortness of breath, choking, tightness in chest

- Target organs: Liver, kidneys, bone marrow, muscles, lungs, central nervous system

Pyrophorics - material capable of igniting automatically when exposed to air

- Types of pyrophorics: boron, diborane, white or yellow phosphorous

- Routes of entry: Absorption, inhalation, ingestion

- Signs and symptoms of exposure: Some pyrophoric materials may break into flame when exposed to air and cause burns to the skin while others may produce an explosion

- Target organs: All parts of the body may be affected in the event of a fire or explosion

Sensitizers - material that can cause an allergic reaction. A person may work with a chemical for a period of time with no allergic reaction. However, once sensitized, the person may experience an allergic reaction after only a brief, low-level exposure to the material

- Types of sensitizers: Turpentine, isocyanates, formaldehyde, chromic acid, chromium and nickel metal, epoxy resin

- Routes of entry: Absorption, inhalation, injection, ingestion

- Signs and symptoms of exposure: Skin rash, puffy eyes, runny nose, watery eyes, coughing, sneezing

- Target organs: Skin, eyes, mucous membranes, respiratory tract

Solvent - material, usually liquid, that dissolves or can dissolve another substance.

- Types of solvents; alcohol, gasoline, diesel fuel, chlorinated hydrocarbons, benzene, methanol, carbon disulfide, acetone

- Routes of entry: Absorption, inhalation, injection, ingestion

- Signs and symptoms of exposure: Skin will appear white and dry because the natural oils have been removed. Some solvents can cause skin irritation, redness dermatitis, and itching. Some organic solvents can cause eye irritation, coughing, and respiratory arrest.

- Target organs: Skin, eyes, central nervous system, lungs, liver, heart 


\section{APPENDIX B：DRAWINGS}

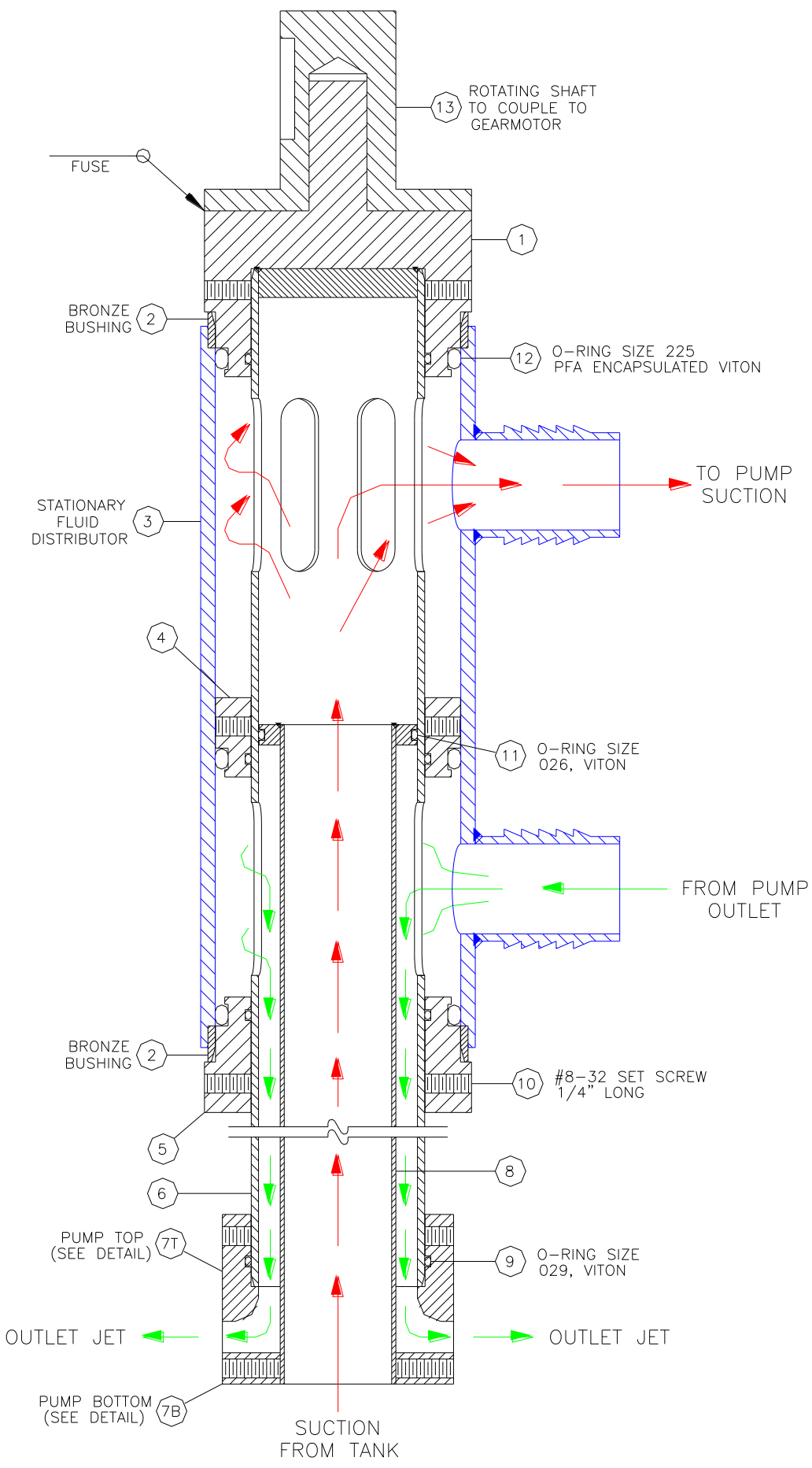

Figure B1: Jet Pump 


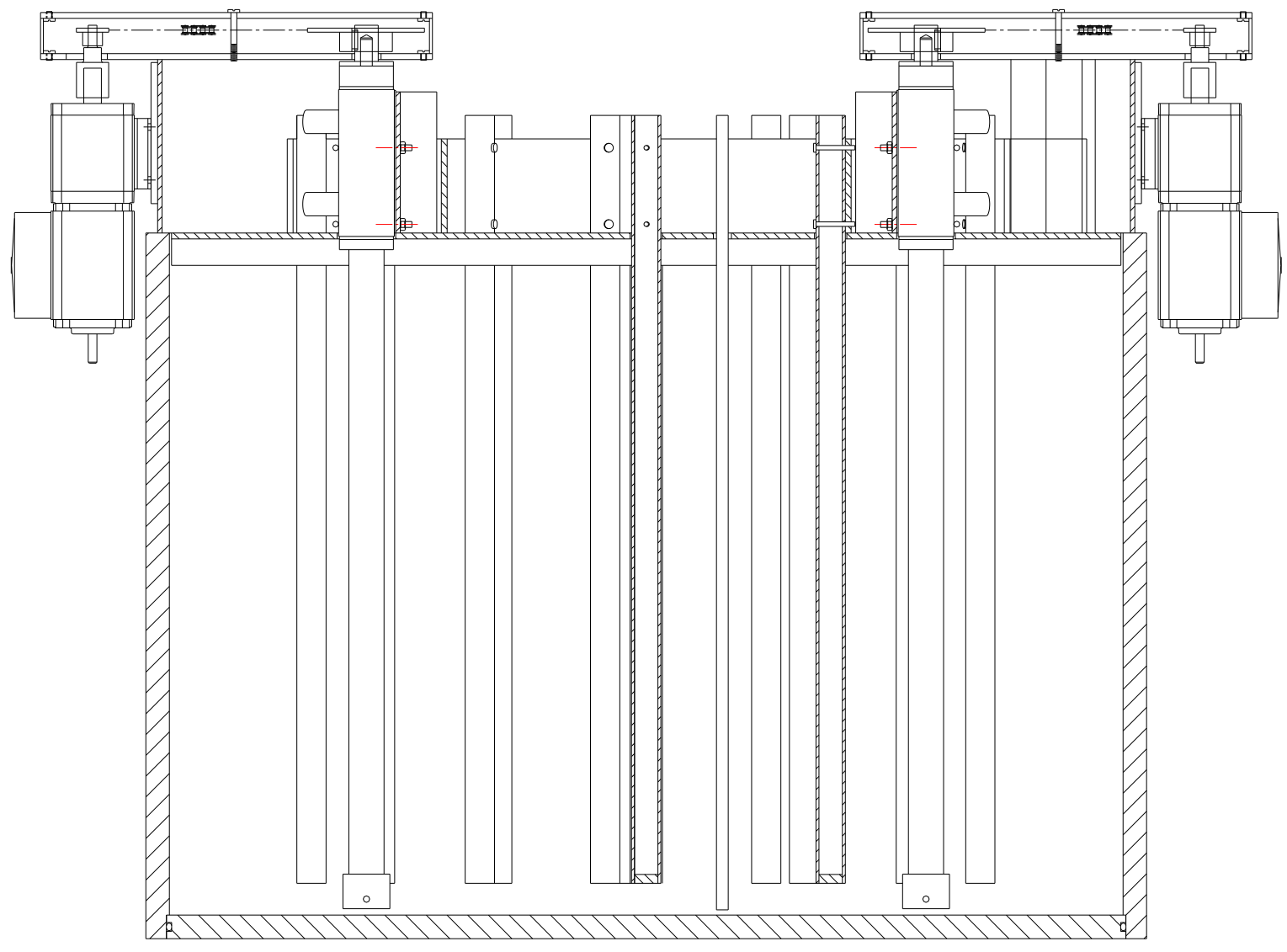

Figure B2: Side View of Obstructions MJP Assembly and Transfer Tubing 


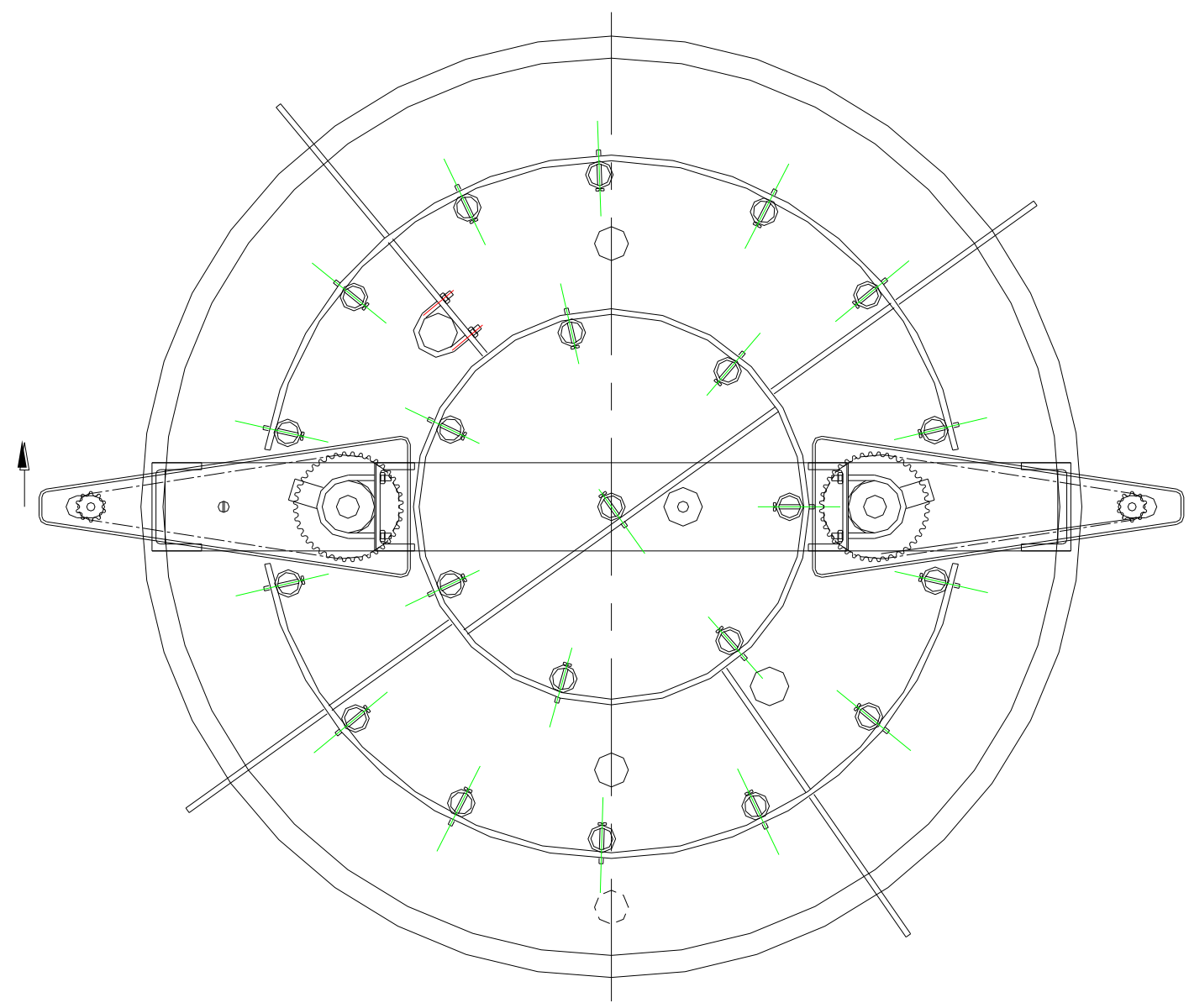

Figure B3: Top View of Obstructions and jet Pump Assembly 


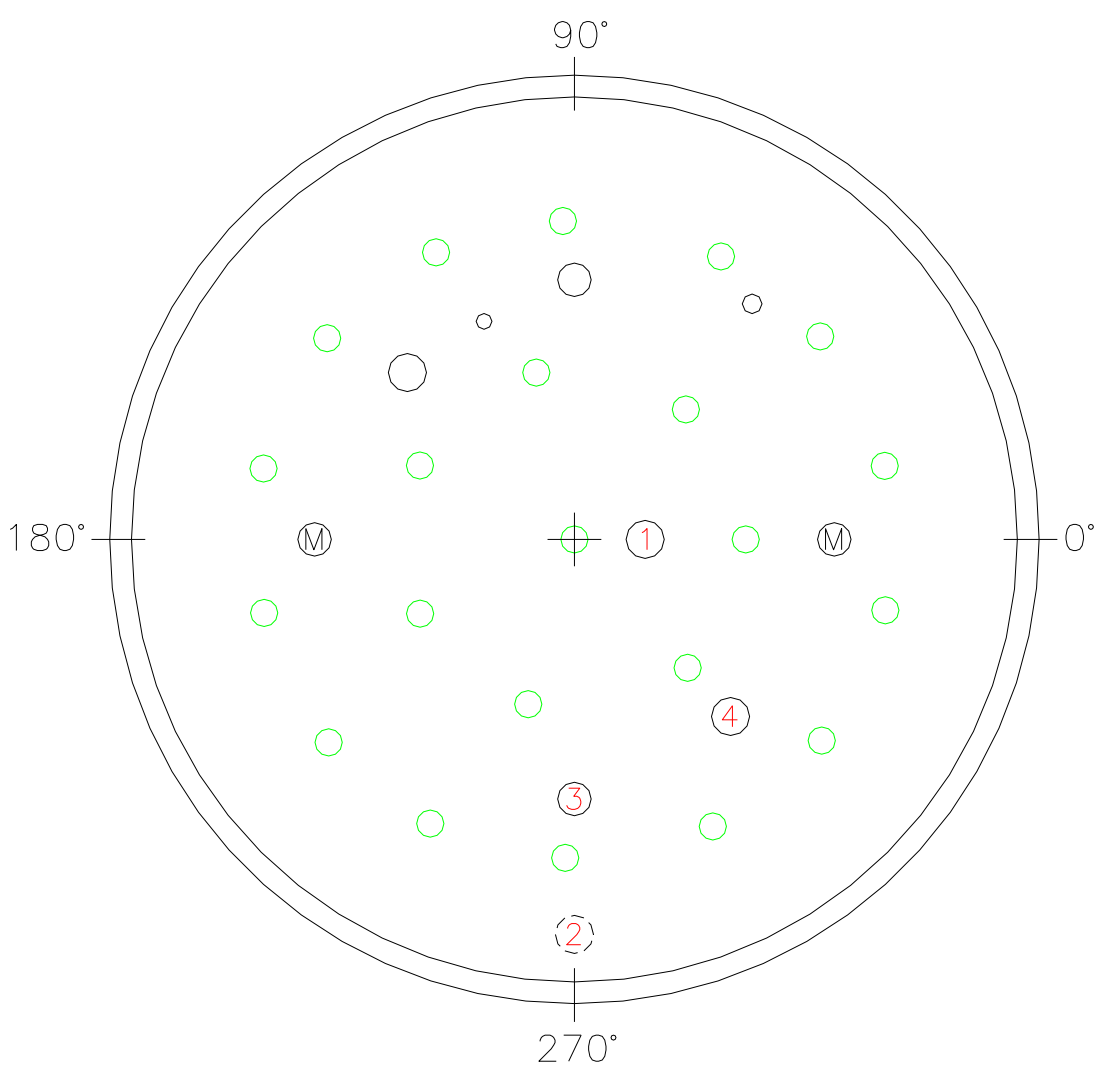

Figure B4: Top View of MDT Transfer Lines locations (Point 1 and 3 tested) 


\section{APPENDIX C: PSD ANALYSIS OF SIC TESTS 11 AND 3.5}

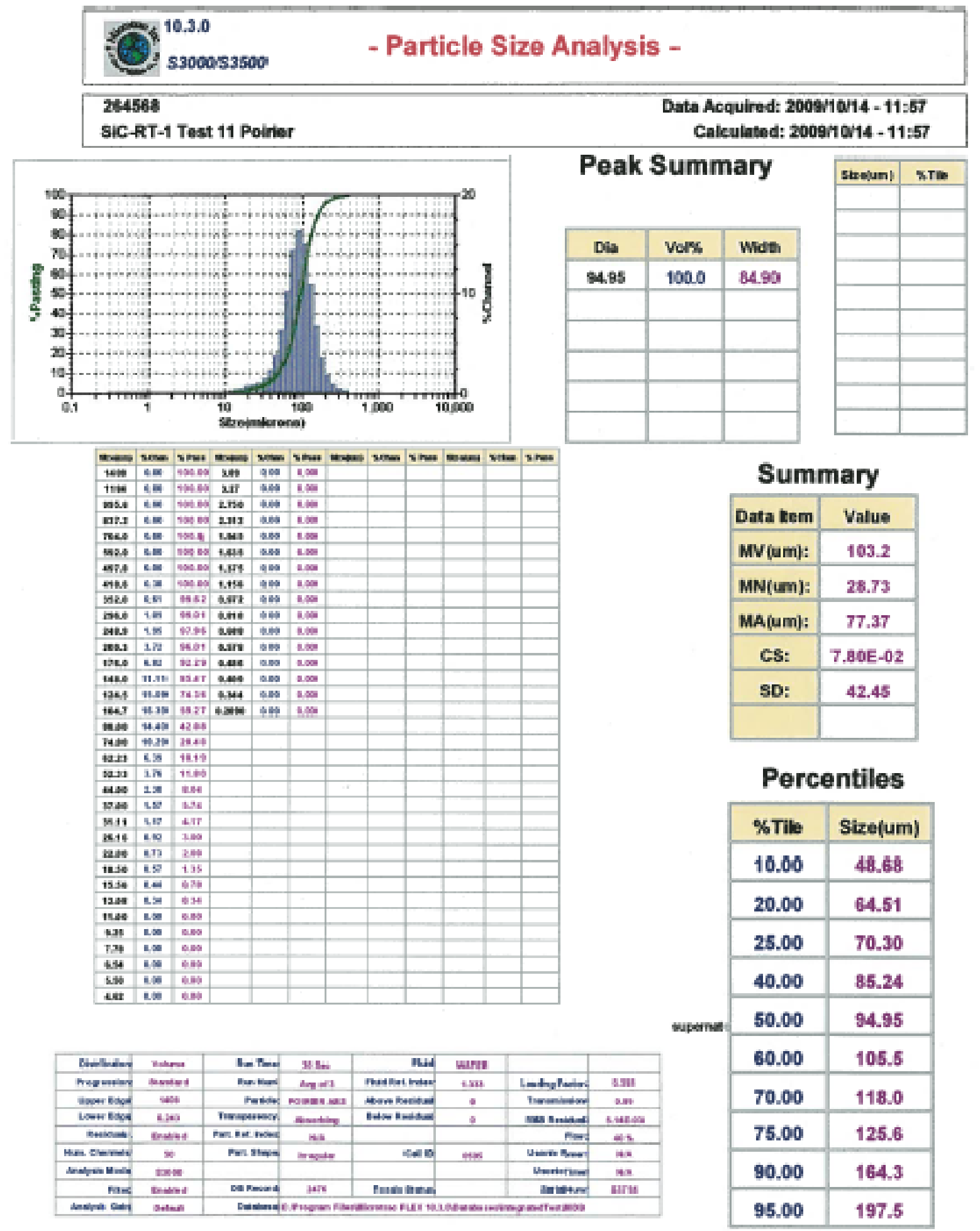


10.3 .0

$83000 / 53500$

- Particle Ŝize Analysis -

254569

BiC-RT-5 Test 11 Poirler

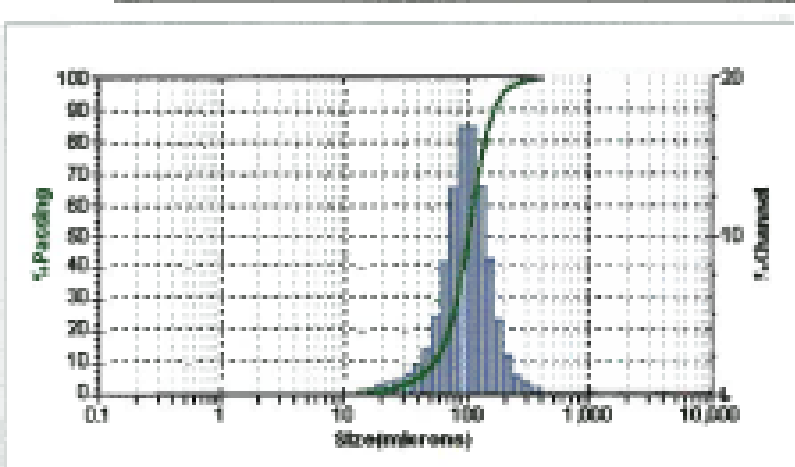

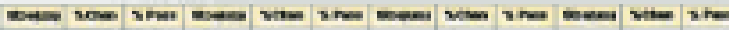

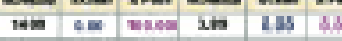

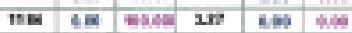

nos 4 an whe 2130 ins 6.60

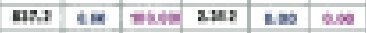

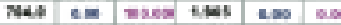

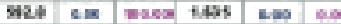

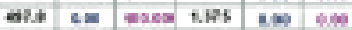

नIL 4 a

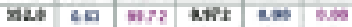

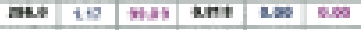

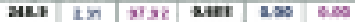

senc 4 L

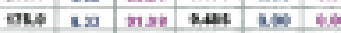

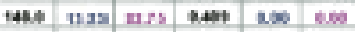

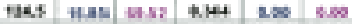

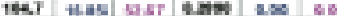

ingo is at wat

Tab te 27 ?

an an in $143 x$

asi in 81

ath sis tis

10.

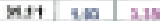

a.t4 G18 212

nat 194 in

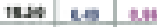

1254 as the

$13 \mathrm{An}$ :

F⿻十 190

$135 \mathrm{sen}$ ase

73 in an

Lis is ate

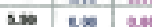

Seg is an
Data Acquired: 2009/1014 - 12:15

Calculated: 2009/10/14 - 12:15

Peak Summary
\begin{tabular}{|c|c|c|}
\hline Dia & vork & Wdat \\
\hline 1020 & 100.0 & 86.37 \\
\hline & & \\
\hline & & \\
\hline & & \\
\hline & & \\
\hline & & \\
\hline
\end{tabular}

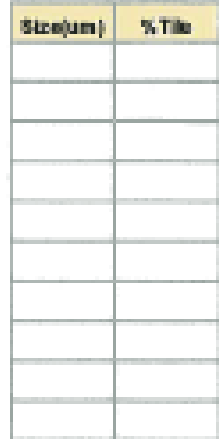

\section{Summary}

\begin{tabular}{|c|c|}
\hline Data kem & Value \\
\hline MV(um): & 105.3 \\
\hline MN(um): & 34.27 \\
\hline MA(um): & 84.32 \\
\hline CS: & $7.10 E-02$ \\
\hline SD: & 43.19 \\
\hline & \\
\hline
\end{tabular}

Percentiles

\begin{tabular}{|c|c|}
\hline \%Tile & Size(um) \\
\hline 10.00 & 53.67 \\
\hline 20.00 & 70.56 \\
\hline 25.00 & 76.62 \\
\hline 40.00 & 92.09 \\
\hline 50.00 & 102.0 \\
\hline 60.00 & 112.6 \\
\hline 70.00 & 125.2 \\
\hline 75.00 & 132.9 \\
\hline 90.00 & 171.2 \\
\hline 95.00 & 203.1 \\
\hline
\end{tabular}


SRNL-STI-2009-00717

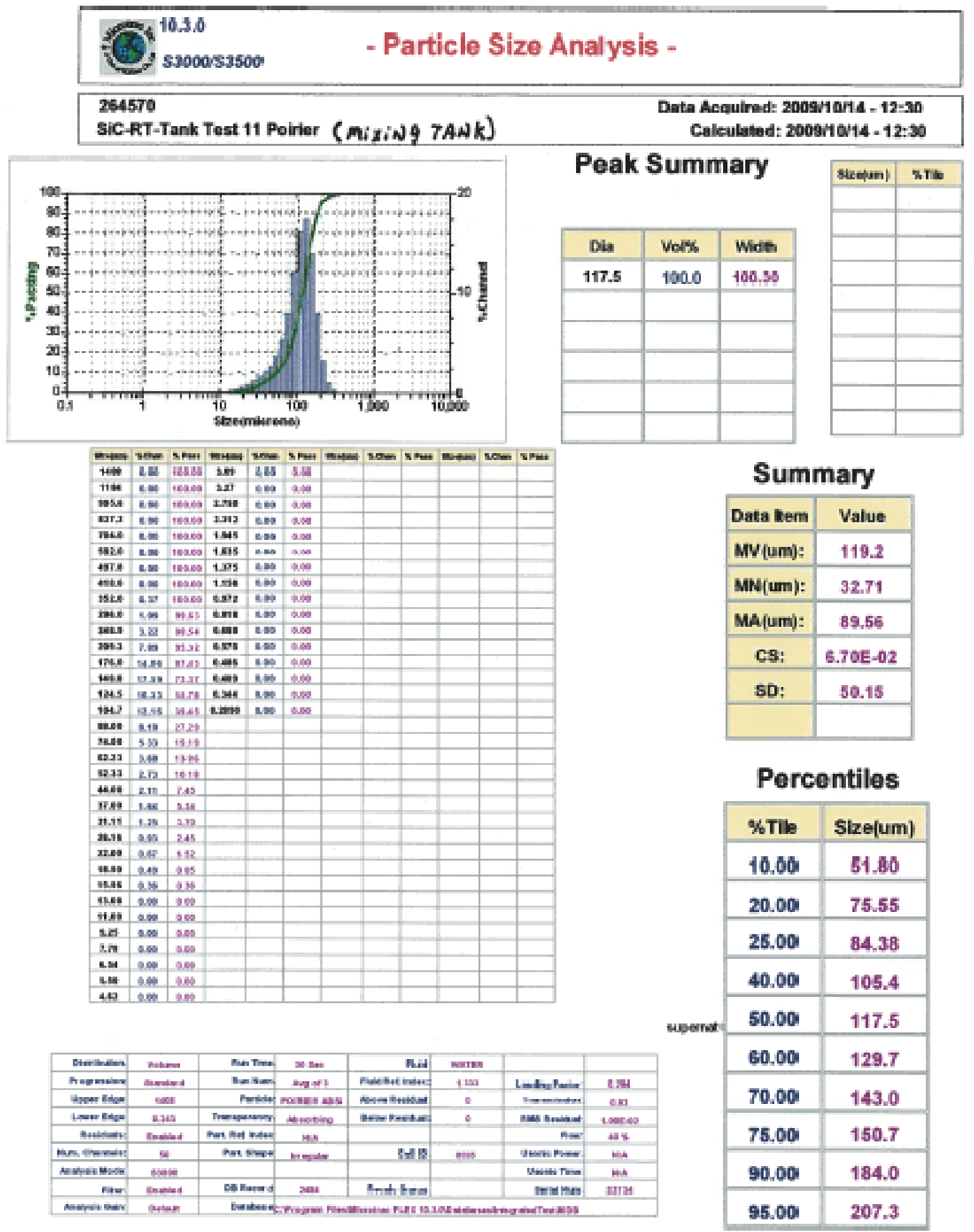




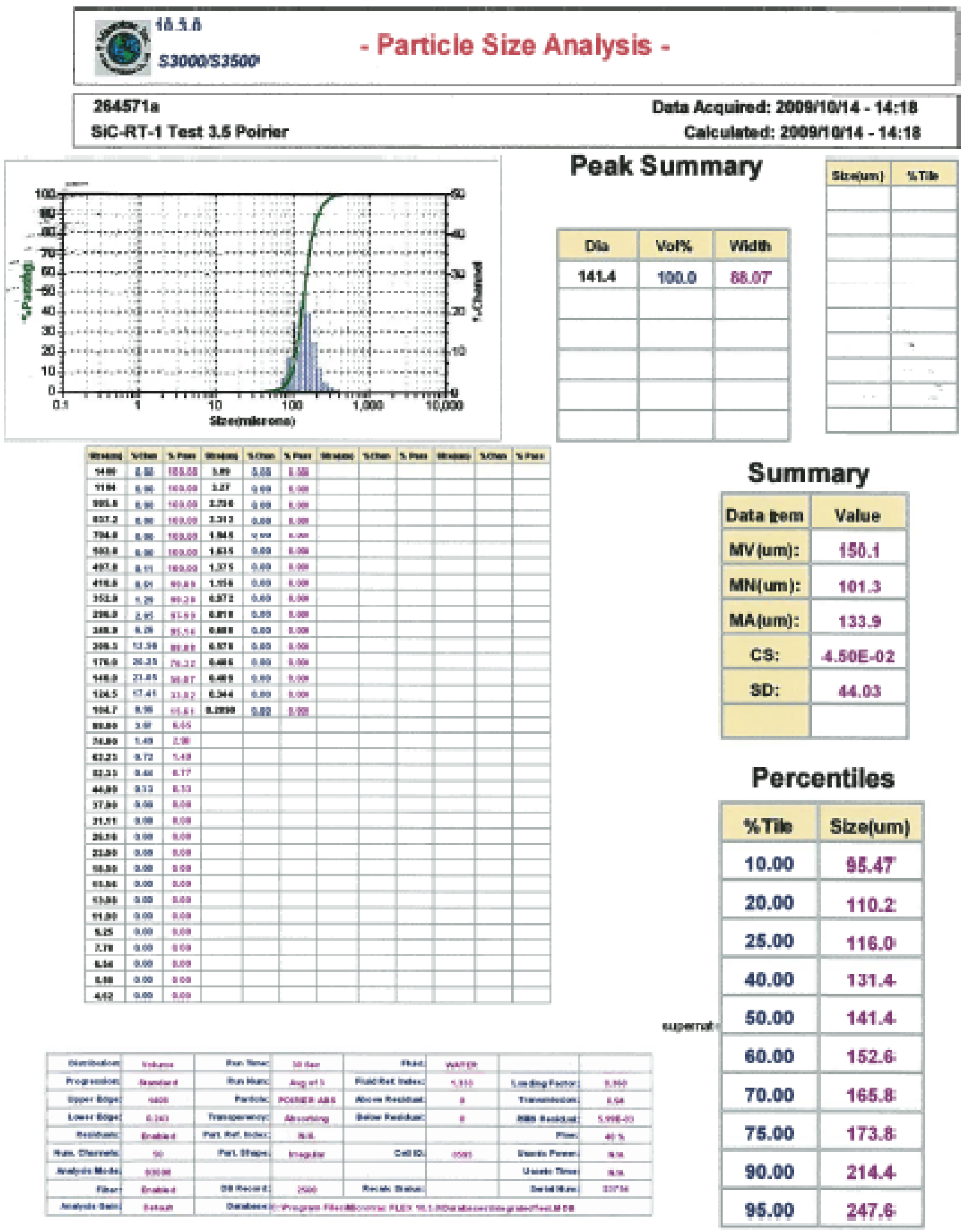


SRNL-STI-2009-00717

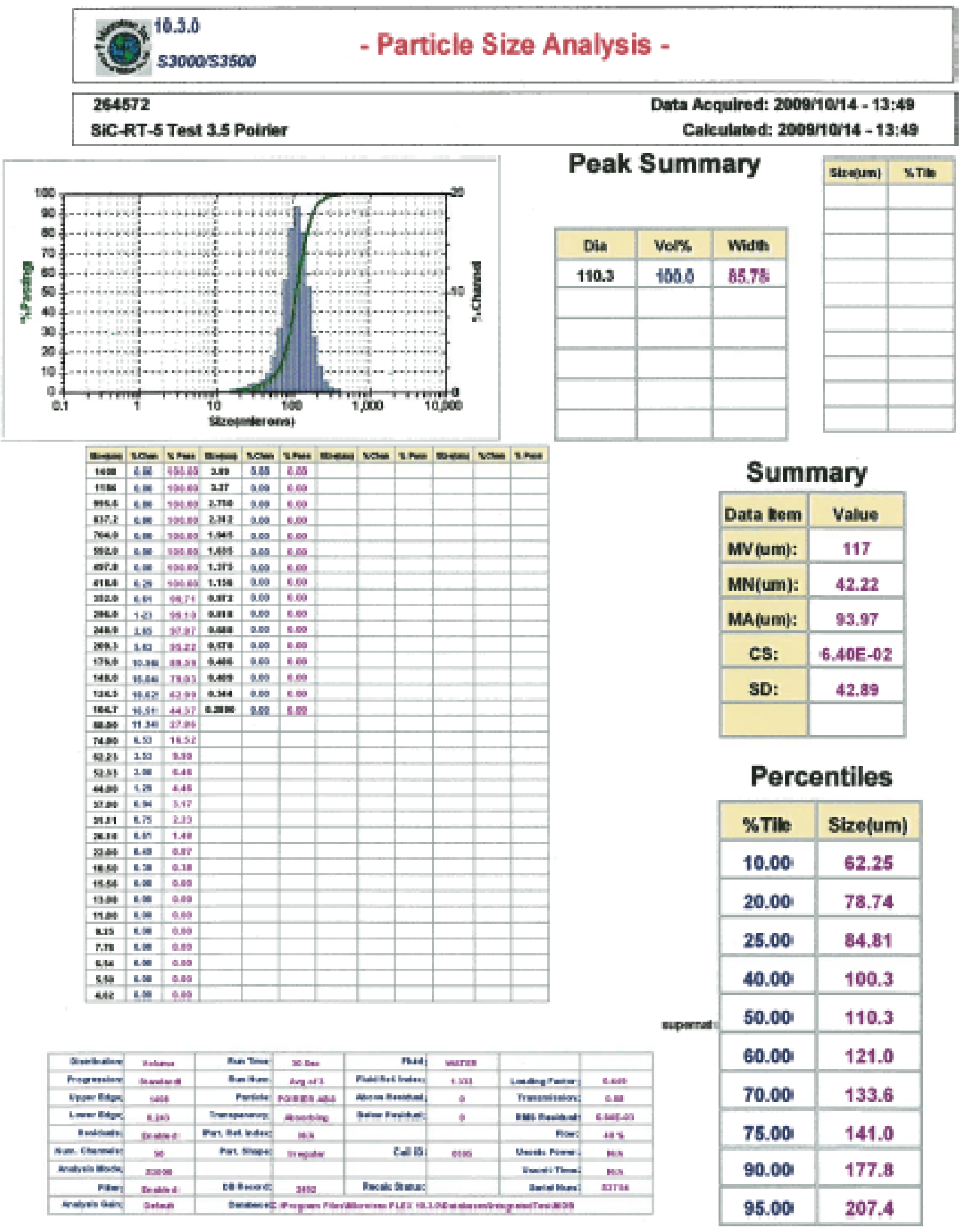


SRNL-STI-2009-00717

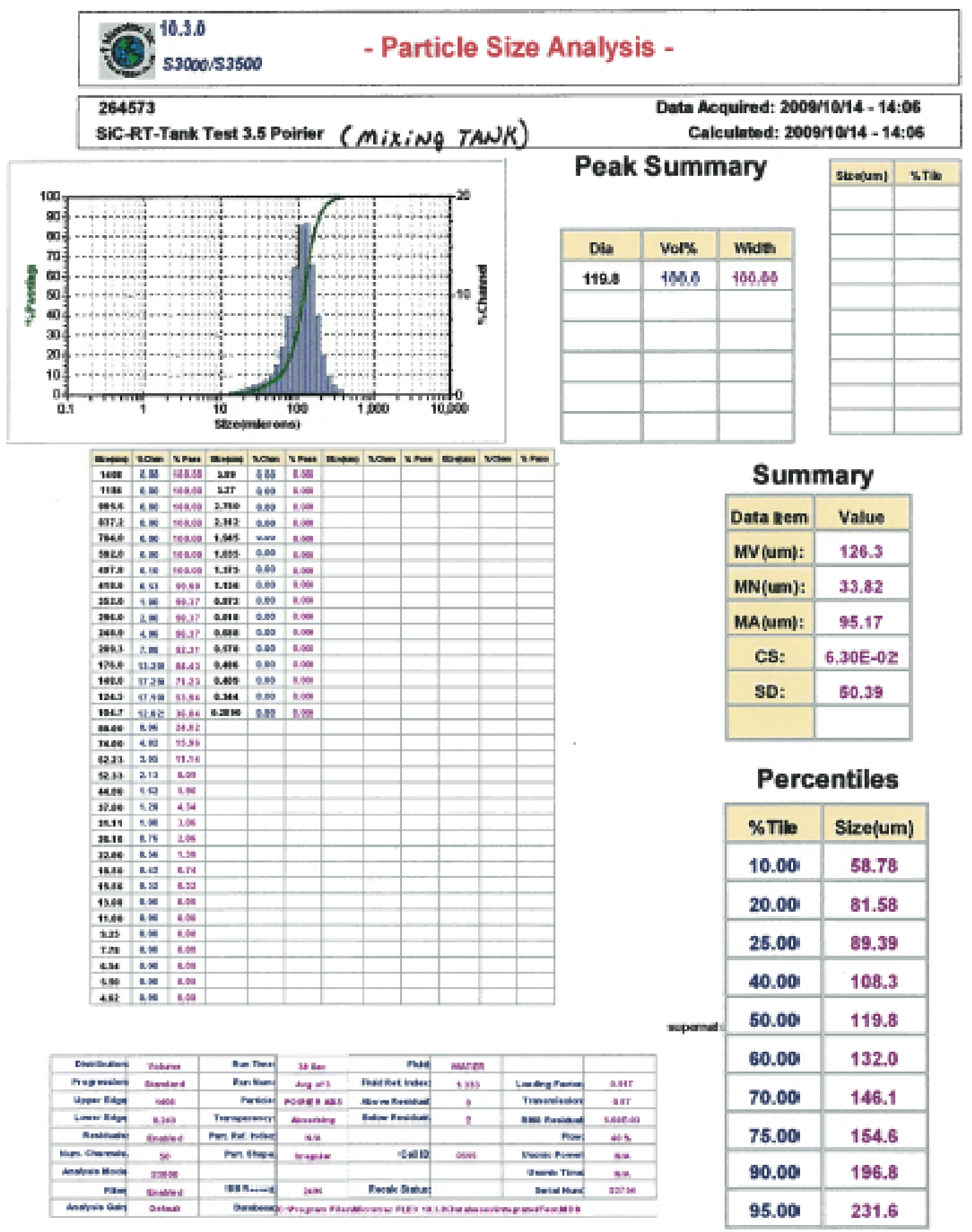

